Supporting Information for

\title{
Contra-thermodynamic Olefin Isomerization by Chain-Walking Hydroboration and Dehydroboration
}

\author{
Steven Hanna, Brandon Bloomer, Nicodemo R. Ciccia, Trevor W. Butcher, Richard J. Conk, \\ John F. Hartwig* \\ Division of Chemical Sciences, Lawrence Berkeley National Laboratory, \\ Department of Chemistry, University of California, Berkeley, CA 94720, United States
}

Email: jhartwig@berkeley.edu 


\section{Table of Contents}

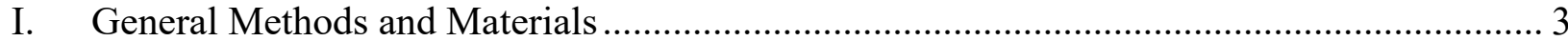

II. Preparation of Potassium Methoxide ............................................................................ 4

III. Table S1 - Dehydroboration of Boronic Ester 2a .................................................. 5

IV. Scheme S1 - Dehydroboration of Boronic Ester 2b................................................ 6

V. Table S2 - Dehydroboration of $2 \mathrm{a}$ in the presence of reagents for hydroboration................ 7

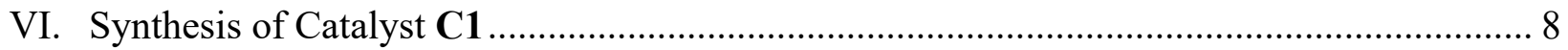

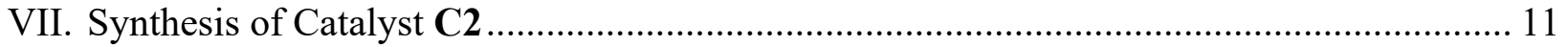

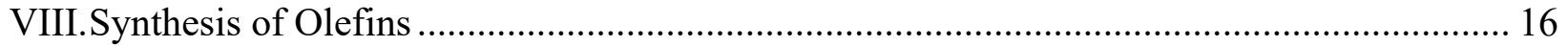

IX. General Procedures for Olefin Isomerizations............................................................ 21

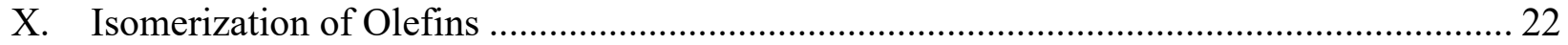

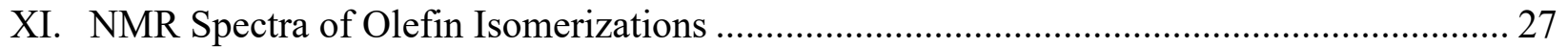

XII. Olefin Isomerization on a 1 mmol Scale.......................................................................... 53

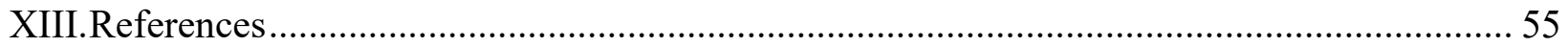




\section{General Methods and Materials}

All air-sensitive manipulations were conducted under an inert atmosphere in nitrogen-filled or argon-filled gloveboxes or by standard Schlenk techniques. All reagents were purchased from commercial suppliers and used as received unless otherwise stated. Potassium methoxide was prepared as described below. Crude reaction mixtures were analyzed by gas chromatography (GC) on an Agilent $7890 \mathrm{GC}$ equipped with an HP-5 column (25 m x $0.20 \mathrm{~mm}$ x $0.33 \mu \mathrm{m}$ film) and an FID detector. Quantitative analysis by GC was conducted with dodecane as an internal standard. The products of catalytic reactions were purified by flash column chromatography with a Teledyne Isco CombiFlash ${ }^{\circledR} R_{f}$ system and RediSep $R_{f}$ Gold ${ }^{T M}$ columns. All NMR spectra were recorded at the University of California, Berkeley NMR facility. NMR spectra were recorded on Bruker AVB400, AVQ-400, AV-500, and AV-600 instruments with operating frequencies of 400, 400, 500, and $600 \mathrm{MHz}$, respectively, and Carbon-13 NMR spectra were recorded on a Bruker AV-600 instrument with a ${ }^{13} \mathrm{C}$ operating frequency of $151 \mathrm{MHz}$. Chemical shifts $(\delta)$ are reported in ppm relative to those of residual solvent signals $\left(\mathrm{CDCl}_{3} \delta=7.26\right.$ for ${ }^{1} \mathrm{H}$ NMR spectra and $\delta=77.16$ for ${ }^{13} \mathrm{C}$ NMR spectra). All reactions that required heat were heated on an IKA stirring plate in a metal heating block or an oil bath. High-resolution mass spectral data were obtained with a Thermo Finnigan LTQ FT Instrument in the QB3/Chemistry Mass Spectrometry Facility, University of California, Berkeley. All NMR spectra of isolated products were recorded in chloroform- $d 3$, and

all NMR spectra of crude reaction mixtures were recorded in a mixture of chloroform- $d 3$ and tetrahydrofuran, as described in the corresponding experimental procedures. 


\section{Preparation of Potassium Methoxide}

In an argon-filled glovebox, a commercial dispersion of potassium hydride in mineral oil was washed thoroughly with copious pentane and dried over a frit to yield pure, free-flowing potassium hydride powder. In the glovebox, an oven-dried round-bottom flask was charged with free-flowing potassium hydride $(8.02 \mathrm{~g}, 200 \mathrm{mmol}, 1$ equiv) and anhydrous THF (100 $\mathrm{mL})$. Anhydrous methanol (9.72 mL, $240 \mathrm{mmol}, 1.2$ equiv) was added dropwise at room temperature with stirring in the glovebox. The reaction was stirred at room temperature in the glovebox for $24 \mathrm{~h}$, at which time bubbling had mostly ceased. The reaction mixture was filtered over a frit, washed with copious THF ( $\sim 500 \mathrm{~mL})$, washed with copious pentane $(\sim 500 \mathrm{~mL})$, and dried under vacuum. This material was used in dehydroboration reactions without further purification. 


\section{Table S1 - Dehydroboration of Boronic Ester 2a}

The dehydroboration sequence was conducted with the elimination step at various temperatures and with various equivalents of $\mathrm{KO}^{t} \mathrm{Bu}$. We found that a minimum of 3 equivalents of $\mathrm{KO}^{t} \mathrm{Bu}$ were required to conduct the elimination, possibly due to the presence of excess iodine after the completion of the iodination. Regardless of the number of equivalents of $\mathrm{KO}^{t} \mathrm{Bu}$ used, the elimination step could be conducted at room temperature.

\begin{tabular}{|c|c|c|c|c|}
\hline \multicolumn{2}{|c|}{$2 a$} & \multicolumn{2}{|l|}{ 2) $\mathrm{KO}^{t} \mathrm{Bu}$} & ta \\
\hline Entry & $\mathrm{KO}^{t} \mathrm{Bu}$ (equiv) & Temp $\left({ }^{\circ} \mathrm{C}\right)$ & Temperature & Yield \\
\hline 1 & 6 & rt & rt & 89 \\
\hline 2 & 6 & 50 & $\mathrm{rt}$ & 94 \\
\hline 3 & 6 & 65 & rt & 93 \\
\hline 4 & 6 & 80 & $\mathrm{rt}$ & 84 \\
\hline 5 & 5 & $\mathrm{rt}$ & rt & 90 \\
\hline 6 & 5 & 50 & $\mathrm{rt}$ & 92 \\
\hline 7 & 5 & 65 & rt & 87 \\
\hline 8 & 5 & 80 & rt & 85 \\
\hline 9 & 4 & $\mathrm{rt}$ & rt & 92 \\
\hline 10 & 4 & 50 & rt & 91 \\
\hline 11 & 4 & 65 & rt & 79 \\
\hline 12 & 4 & 80 & rt & 87 \\
\hline 13 & 3 & $\mathrm{rt}$ & $\mathrm{rt}$ & 91 \\
\hline 14 & 3 & 50 & rt & 92 \\
\hline 15 & 3 & 65 & $\mathrm{rt}$ & 91 \\
\hline 16 & 3 & 80 & rt & 90 \\
\hline 17 & 0 & $\mathrm{rt}$ & 50 & $91^{a}$ \\
\hline 18 & 0 & 50 & 65 & $91^{a}$ \\
\hline 19 & 0 & 65 & 80 & $92^{a}$ \\
\hline 20 & 0 & 80 & 100 & $92^{\mathrm{a}}$ \\
\hline
\end{tabular}

Conditions:

Step 1: KOMe (2 equiv), THF (100 $\mu \mathrm{L}), 15 \mathrm{~min}, \mathrm{rt} ; \mathrm{I}_{2}$ (2 equiv), THF (100 $\left.\mu \mathrm{L}\right), 15 \mathrm{~min}, \mathrm{rt}$; KO ${ }^{t} \mathrm{Bu}$ (1 equiv), THF (100 $\mu \mathrm{L}) ; 15$ min, rt. Step 2: $\mathrm{KO}{ }^{t} \mathrm{Bu}, 22 \mathrm{~h}$, THF $(200 \mu \mathrm{L})$. ${ }^{\mathrm{a}}{ }^{2}$ ield of alkyl iodide. 


\section{Scheme S1 - Dehydroboration of Boronic Ester 2b}

The combined yield of alkyl iodide $\mathbf{3 b}$ and terminal olefin $\mathbf{4 b}$ was $93 \%$ when the $\mathrm{KOMe}, \mathrm{I}_{2}$, and $\mathrm{KO}^{t} \mathrm{Bu}$ were added portionwise over two iterations.

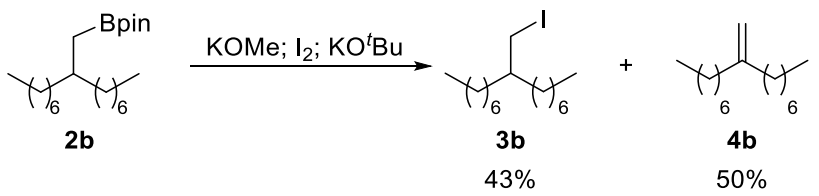

Conditions: $\mathrm{KOMe}, \mathrm{I}_{2}$, and $\mathrm{KO}^{t} \mathrm{Bu}$ were added portionwise over two iterations. The reaction mixture was stirred for $5 \mathrm{~min}$ at room temperature between the addition of each reagent. The reagents were added in the following order. KOMe (2 equiv), THF $(100 \mu \mathrm{L}), 5 \mathrm{~min}, \mathrm{rt}$; $\mathrm{I}_{2}(1.5$ equiv), THF (100 $\mu \mathrm{L}), 5$ min, rt; KO ${ }^{t} \mathrm{Bu}$ (1 equiv), 1 h; KOMe (2 equiv), THF $(100 \mu \mathrm{L}), 5$ min, rt; $\mathrm{I}_{2}(1.5$ equiv), THF (100 $\mu \mathrm{L}), 5$ min, rt; KOtBu (1 equiv), $1 \mathrm{~h}$ 


\section{Table S2 - Dehydroboration of 2a in the presence of reagents for hydroboration}

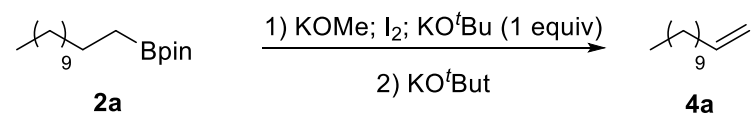

\begin{tabular}{ccc} 
Entry & deviation from conditions & Yield \\
\hline 1 & none & 90 \\
2 & added 0.1 equiv HBpin & 86 \\
3 & added 0.5 equiv HBpin & 67 \\
4 & added MTBE & 85 \\
5 & added MTBE + 0.1 equiv HBPin & 86 \\
6 & added MTBE + 0.5 equiv HBPin & 64 \\
7 & added MTBE + C1 & 60 \\
8 & added MTBE + C1 + 0.5 equiv HBpin & 43
\end{tabular}

Step 1: KOMe (2 equiv), THF (100 $\mu \mathrm{L}), 15$ min, rt; $\mathrm{I}_{2}(2$ equiv), THF (100 $\mu \mathrm{L}), 15 \mathrm{~min}, \mathrm{rt}$; KOtBu (1 equiv), THF (100 $\left.\mu \mathrm{L}\right)$; $15 \mathrm{~min}$, rt. Step 2: KOtBu, $22 \mathrm{~h}$, THF $(200 \mu \mathrm{L})$. aYield of alkyl iodide. 


\section{Synthesis of Catalyst C1}

\section{[( $\left.\left.{ }^{\mathrm{IPr}} \mathrm{DI}\right) \mathrm{CoCl}_{2}\right](\mathrm{S} 1)$}
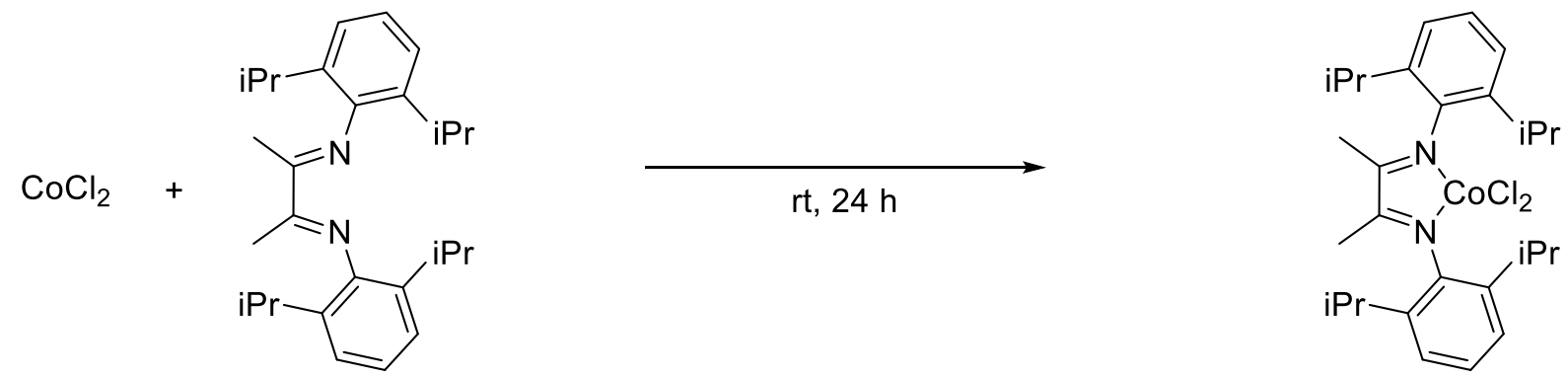

$2.91 \mathrm{~g}, 91 \%$

The following procedure was adapted from that of Thomas and coworkers. ${ }^{1}$ In a nitrogenfilled glovebox, an oven-dried $500 \mathrm{~mL}$ round-bottom flask equipped with a stir bar was charged with (2E)-N-[(E)-(2,6-diisopropylphenylimino)butan-2-ylidene]-2,6-diisopropyl-benzenamine (2.43 g, $6.00 \mathrm{mmol}, 1$ equiv, prepared according to the literature ${ }^{1}$ ), anhydrous cobalt dichloride (779 mg, $6.00 \mathrm{mmol}, 1$ equiv), and THF $(90 \mathrm{~mL})$. The reaction mixture was stirred at room temperature for $48 \mathrm{~h}$ and concentrated in vacuo. Diethyl ether $(100 \mathrm{~mL})$ was added. The resulting precipitate was collected by filtration and washed with diethyl ether $(200 \mathrm{~mL})$ to yield $\mathbf{S 1}$ as a dark-green solid (2.91 g, 91\% yield). The ${ }^{1} \mathrm{H}$ NMR spectrum matched that in the literature. ${ }^{1}$ 


\section{$\left[\left({ }^{\mathrm{IPr} D I}\right) \mathrm{CoCl}\right]_{2}(\mathrm{S2})$}
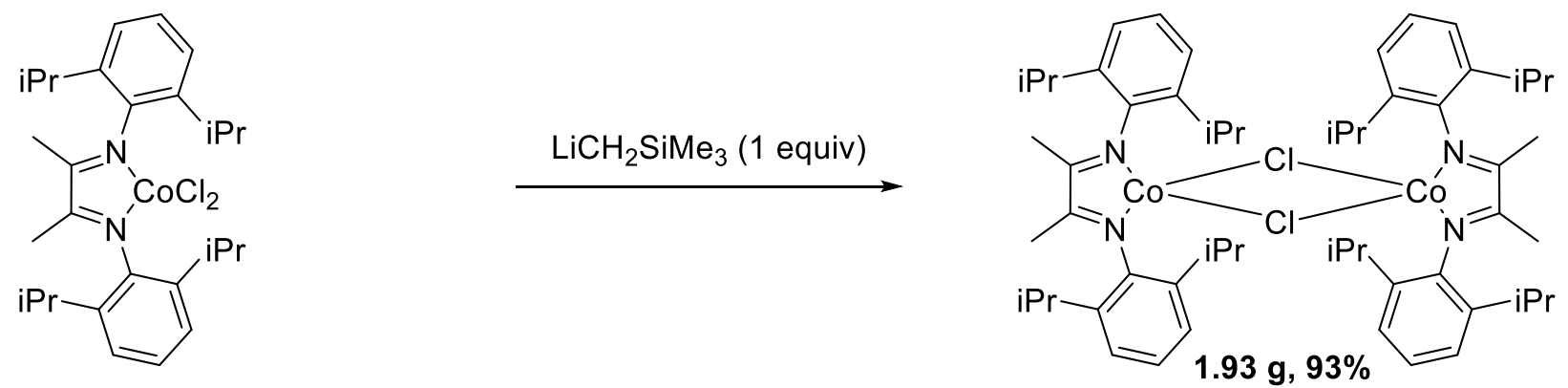

The following procedure was adapted from that of Chirik and coworkers. ${ }^{2}$ In a nitrogenfilled glovebox, a solution of $\left.\left[{ }^{(\mathrm{Pr} D I}\right) \mathrm{CoCl}_{2}\right](\mathbf{S 1}, 2.15 \mathrm{~g}, 4.03 \mathrm{mmol}, 1.00$ equiv) in diethyl ether $(60 \mathrm{~mL})$ was prepared in a $250 \mathrm{~mL}$ round-bottom flask and cooled in a cold well in the drybox floor with a dry ice/acetone bath. A separate solution of $\mathrm{LiCH}_{2} \mathrm{SiMe}_{3}(4.0 \mathrm{~mL}, 1.0 \mathrm{M}$ in pentane, $4.0 \mathrm{mmol}, 1.0$ equiv) in diethyl ether $(30 \mathrm{~mL})$ was chilled at $-25^{\circ} \mathrm{C}$ in a glovebox freezer and added dropwise with stirring over $40 \mathrm{~min}$ to the round-bottom flask containing the solution of [( $\left.\left.{ }^{\mathrm{IPr} D I}\right) \mathrm{CoCl}_{2}\right]$. Throughout the $40 \mathrm{~min}$ addition of $\mathrm{LiCH}_{2} \mathrm{SiMe}_{3}$, the round-bottom flask was kept in the cold well cooled with a dry ice/acetone bath. The round-bottom flask was removed from the cold well and stirred at room temperature for $1 \mathrm{~h}$. The reaction mixture was filtered, and the filtrate was concentrated in vacuo. The residue was washed with several small aliquots of cold pentane (approximately $30 \mathrm{~mL}$ total) and collected on a frit to yield $\mathbf{S 2}$ as a dark-green powder (1.87 g, 93\% yield). This material is paramagnetic, and a ${ }^{1} \mathrm{H}$ NMR spectrum was not recorded. This material was converted to catalyst $\mathbf{C 1}$ without further purification. 


\section{$\left[\left({ }^{\mathrm{IPr}} \mathrm{DI}\right) \mathbf{C o}\left(\boldsymbol{\eta}^{3}-\mathrm{C}_{3} \mathbf{H}_{5}\right)\right](\mathbf{C 1})$}

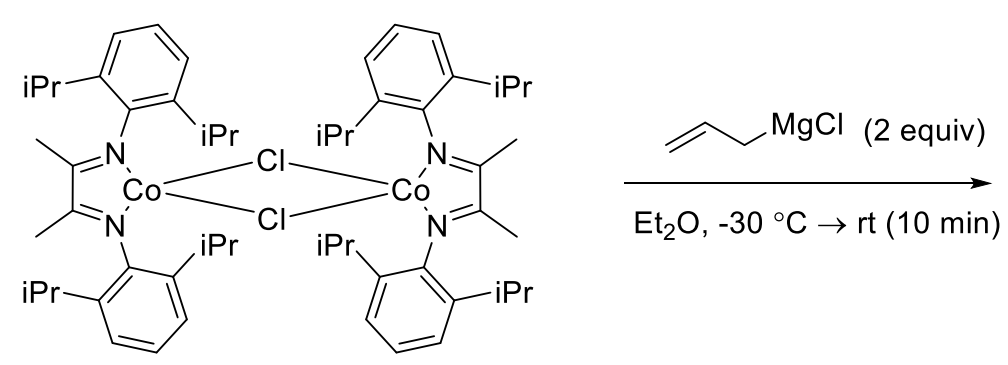

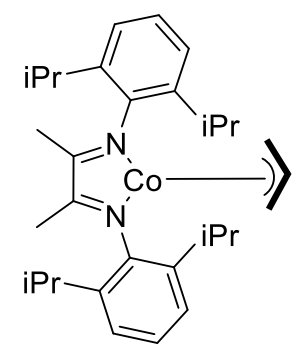

$1.6 \mathrm{~g}, 85 \%$

The following procedure was adapted from that of Chirik and coworkers. ${ }^{2}$ In a nitrogen-filled glovebox, a solution of $\left.\left[{ }^{\mathrm{IPr} D I}\right) \mathrm{CoCl}\right]_{2}(\mathbf{S 2}, 1.87 \mathrm{~g}, 1.87 \mathrm{mmol}, 1.00$ equiv) in diethyl ether (140 $\mathrm{mL}$ ) was prepared in a $500 \mathrm{~mL}$ round-bottom flask and cooled in a cold well in the drybox floor with a dry ice/acetone bath. A solution of allylmagnesium chloride (1.87 mL, 2.0 M in THF, 3.74 mmol, 2.0 equiv) in diethyl ether $(30 \mathrm{~mL})$ was added dropwise with stirring over 15 min to the round-bottom flask containing the solution of $\left.\left[{ }^{[\mathrm{Pr}} \mathrm{DI}\right) \mathrm{CoCl}_{2}\right]$. Throughout the 15 min addition of allylmagnesium chloride, the round-bottom flask was kept in the cold well cooled with a dry ice/acetone bath. The round-bottom flask was removed from the cold well and stirred at room temperature for $80 \mathrm{~min}$. The reaction mixture was filtered, and the filtrate was concentrated in vacuo to yield $\mathbf{C} 1$ as a dark-blue-green solid (1.60 g, 85\% yield). This material was used in catalytic reactions without further purification. The ${ }^{1} \mathrm{H}$ NMR spectrum matched that in the literature. $^{2}$ 


\section{Synthesis of Catalyst C2}

\section{2,6-Dibromo-4-(1-pyrrolidinyl)-pyridine (S3)}

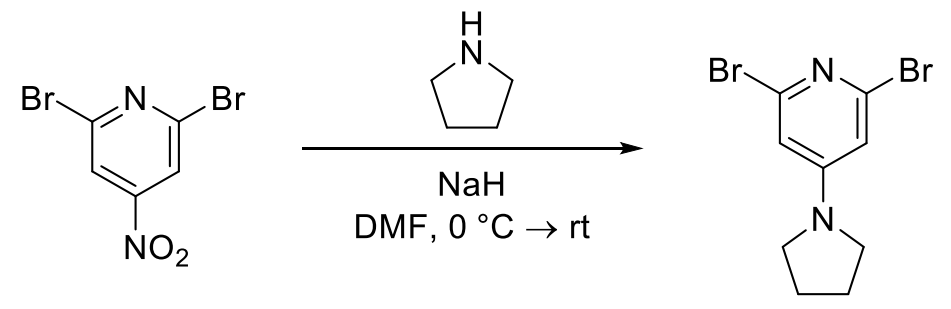

The following procedure was adapted from that of Kanbara and coworkers. ${ }^{3}$

In an argon-filled glovebox, pure, free-flowing sodium hydride $(3.60 \mathrm{~g}, 150 \mathrm{mmol}, 3.06$ equiv, the commercial $60 \%$ dispersion in mineral oil was washed thoroughly with pentane to obtain the pure powder) and DMF $(100 \mathrm{~mL})$ were added to an oven-dried $500 \mathrm{~mL}$ round bottom flask. The flask was capped with a septum, removed from the glovebox, and cooled in an ice bath. A solution, prepared in the glovebox, of 2,6-dibromo-4-nitropyridine (13.8 g, $49.1 \mathrm{mmol}, 1$ equiv) in DMF $(40 \mathrm{~mL})$ was added dropwise with stirring at $0{ }^{\circ} \mathrm{C}$ under a flow of nitrogen. Pyrrolidine $(4.20 \mathrm{~mL}$, $49.9 \mathrm{mmol}, 1.02$ equiv) was added dropwise with stirring at $0{ }^{\circ} \mathrm{C}$ under a flow of nitrogen. The mixture was stirred at $0{ }^{\circ} \mathrm{C}$ for approximately $2 \mathrm{~h}$ before the ice melted. After the ice melted, the mixture was stirred for an additional $15 \mathrm{~h}$ at room temperature. The resulting mixture was cooled in the same ice bath and carefully quenched with water $(40 \mathrm{~mL})$ under a flow of nitrogen. An additional $200 \mathrm{~mL}$ of water was added, and the mixture was extracted into ethyl acetate $(300 \mathrm{~mL}$, $2 \mathrm{x}$ then $150 \mathrm{~mL}, 5 \mathrm{x}$ ). Note: conducting the extraction with large solvent volumes was preferable to using smaller solvent volumes with salts and/or brine added to the aqueous layer because the latter method does not remove as much DMF as the former method. The combined extracts were concentrated in vacuo to a volume of approximately $500 \mathrm{~mL}$, washed with brine $(100 \mathrm{~mL}, 1 \mathrm{x})$ to remove residual DMF, dried over sodium sulfate, and concentrated in vacuo to give a dark-red solid, which was recrystallized from hot ethyl acetate. Note: on smaller scales, recrystallization is unnecessary. The mother liquor was concentrated and purified by flash column chromatography on silica gel ( $\sim 80$ g silica, gradient elution: $5 \rightarrow 20 \%$ ethyl acetate/hexane) to afford $\mathbf{S 3}$ (8.87 g, $59 \%$ yield) as a pink, crystalline solid. The ${ }^{1} \mathrm{H}$ NMR spectrum matched that in the literature. ${ }^{3}$ 


\section{2,6-Diacetyl-4-(1-pyrrolidinyl)-pyridine (S4)}

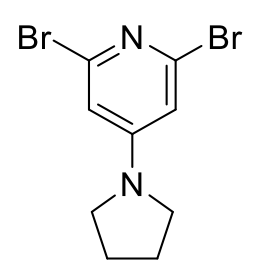
1) $\mathrm{O}^{n} \mathrm{Bu}, \mathrm{Pd}(\mathrm{OAc})_{2}, \mathrm{dppp}$ $\mathrm{NaHCO}_{3}, \mathrm{EtOH}, 120^{\circ} \mathrm{C}$
2) $\mathrm{H}_{3} \mathrm{O}^{+}$

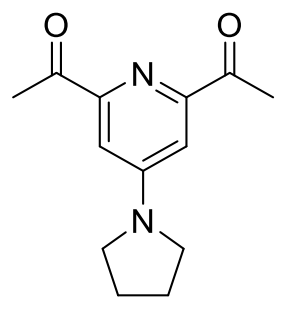

The following procedure was adapted from that of Kobata and coworkers. ${ }^{4}$

In a argon-filled glovebox (nitrogen-filled glovebox also acceptable), an oven-dried $120 \mathrm{~mL}$ pressure tube (selected due to buildup of $\mathrm{CO}_{2}$ from $\mathrm{NaHCO}_{3}$ and of ethanol vapor) was sequentially charged with dppp (441 mg, $1.07 \mathrm{mmol}, 10.7 \mathrm{~mol} \%$ ), Pd(OAc) 2 (180 mg, $0.800 \mathrm{mmol}$, $8.00 \mathrm{~mol} \%$ ), thoroughly degassed ethanol (20 mL), 2,6-dibromo-4-(1-pyrrolidinyl)-pyridine (S3, $3.06 \mathrm{~g}, 10.0 \mathrm{mmol}, 1.00$ equiv), thoroughly degassed butyl vinyl ether (10.6 mL, $81.9 \mathrm{mmol}, 8.19$ equiv), and $\mathrm{NaHCO}_{3}\left(5.04 \mathrm{~g}, 60.0 \mathrm{mmol}, 6.00\right.$ equiv). The reaction mixture was heated at $120^{\circ} \mathrm{C}$ for $24 \mathrm{~h}$. The reaction was monitored by GCMS, with aliquots removed at room temperature inside an argon-filled glovebox. Upon completion of the reaction after $24 \mathrm{~h}$ (no starting material or monoHeck products detected), the reaction mixture was filtered and washed with ethanol $(140 \mathrm{~mL})$. Aqueous $\mathrm{HCl}$ (6 M, $30 \mathrm{~mL}, 180 \mathrm{mmol}, 18.0$ equiv) was added to the filtrate, and the mixture was stirred at room temperature. The progress of the hydrolysis was monitored by GCMS. Upon completion of the reaction after $24 \mathrm{~h}$, the reaction mixture was concentrated to a volume of approximately $70 \mathrm{~mL}$. Sodium hydroxide $(6 \mathrm{M}, \sim 500 \mathrm{~mL})$ was added until a pH of 13 was reached, and the reaction mixture was extracted into ethyl acetate $(5 \mathrm{x}, 150 \mathrm{~mL})$. The combined extracts were recrystallized from hot ethyl acetate (note: on smaller scales recrystallization is unnecessary), and the mother liquor was purified by flash column chromatography on silica gel ( $\sim 60 \mathrm{~g}$ silica, gradient elution: $10 \rightarrow 25 \%$ ethyl acetate/hexane) to afford $\mathbf{S 4}(1.28 \mathrm{~g}, 55 \%$ yield) as a white solid. The ${ }^{1} \mathrm{H}$ NMR spectrum matched that in the literature. ${ }^{4}$ 


\section{4-pyrr- ${ }^{\text {Mes PDI (S5) }}$}

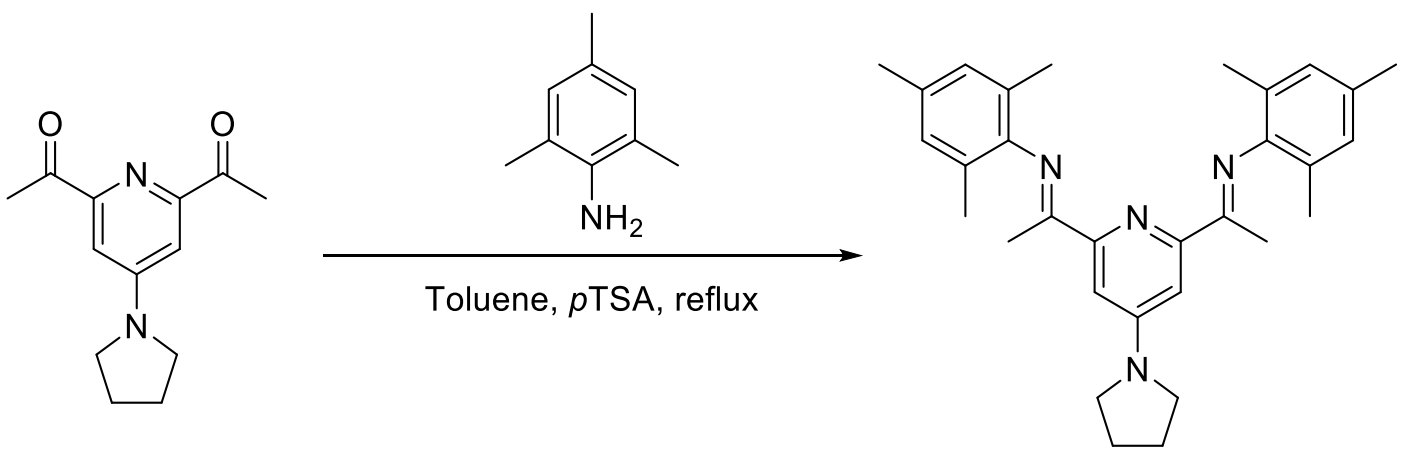

The following procedure was adapted from that of Chirik and coworkers. ${ }^{5}$

In an argon-filled glovebox, 2,6-diacetyl-4-(1-pyrrolidinyl)-pyridine (S4, $1.28 \mathrm{~g}, 5.52 \mathrm{mmol}, 1.00$ equiv), toluene (65 mL, dry and degassed), 2,4,6-trimethylaniline (1.86 mL, $13.3 \mathrm{mmol}, 2.40$ equiv) and $p$-toluenesulfonic acid (7.4 $\mathrm{mg}, 0.039 \mathrm{mmol}, 7.1 \mathrm{~mol} \%$ ) were added to an oven-dried $250 \mathrm{~mL}$ round-bottom flask. The flask was capped with a septum, removed from the glovebox, placed under a positive flow of nitrogen, fitted with a Dean-Stark apparatus, and heated at $130{ }^{\circ} \mathrm{C}$ for $48 \mathrm{~h}$. The reaction was monitored by GCMS. The mixture was concentrated by rotary evaporation outside of the glovebox, and the resulting residue was brought back into the glovebox and washed with a minimal amount of anhydrous methanol ( $9 \mathrm{~mL}$ total, $\sim 1 \mathrm{~mL}$ aliquots at a time) to yield S5 (2.20 g, 85\% yield) as a brown solid. The ${ }^{1} \mathrm{H}$ NMR spectrum matched that in the literature. ${ }^{5}$ 
[(4-pyrr- $\left.\left.{ }^{\text {Mes }} \mathrm{PDI}\right) \mathrm{CoCl}_{2}\right](\mathrm{S6})$

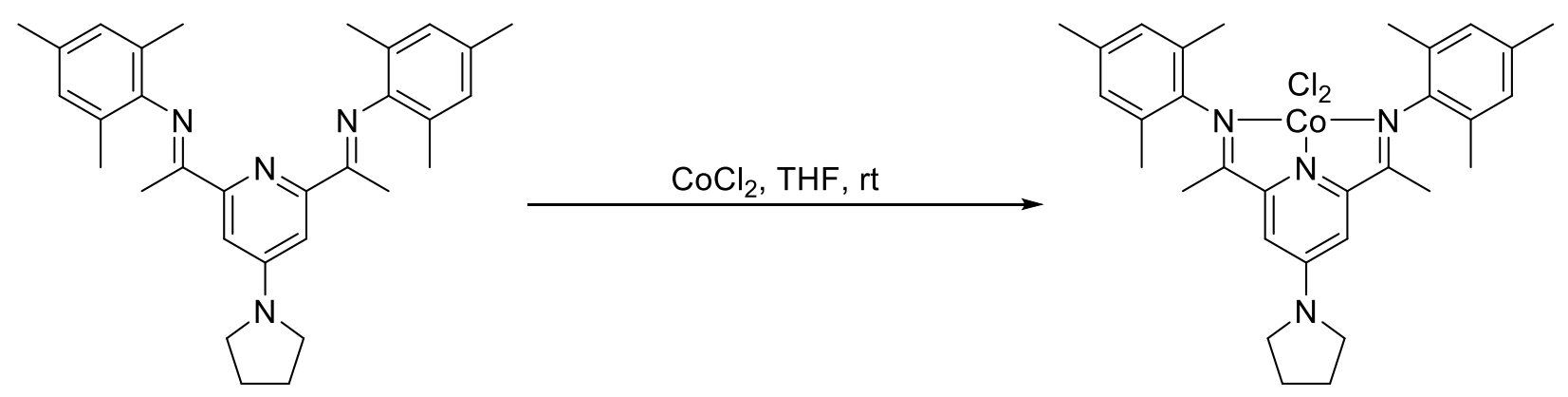

The following procedure was adapted from that of Chirik and coworkers. ${ }^{5}$

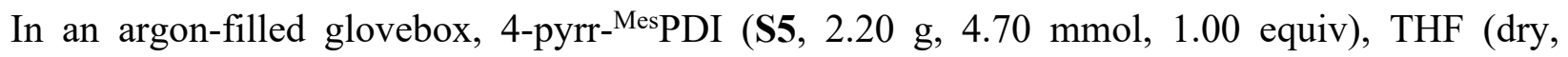
degassed, $100 \mathrm{~mL})$, and $\mathrm{CoCl}_{2}(0.611 \mathrm{~g}, 4.70 \mathrm{mmol}, 1.00$ equiv $)$ were added to an oven-dried 250 $\mathrm{mL}$ round-bottom flask and stirred at room temperature for $24 \mathrm{~h}$. The reaction mixture was concentrated in vacuo, and the residue was washed with diethyl ether $(\sim 60 \mathrm{~mL})$ to afford $\mathbf{S 6}(2.74$ g, $98 \%$ yield) as a bright, green powder. The ${ }^{1} \mathrm{H}$ NMR spectrum matched that in the literature. ${ }^{5}$ 
[(4-pyrr- $\left.{ }^{\text {Mes PDI)CoCH}}\right](\mathrm{C2})$

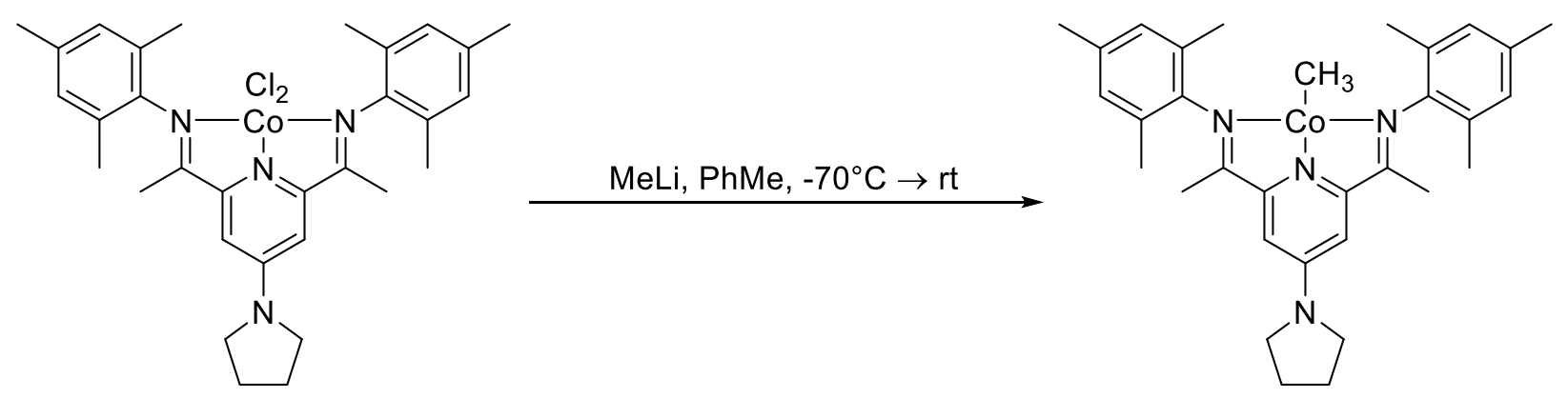

The following procedure was adapted from that of Chirik and coworkers. ${ }^{5}$

In a nitrogen-filled glovebox, a solution of [(4-pyrr- $\left.\left.{ }^{\text {Mes }} \mathrm{PDI}\right) \mathrm{CoCl}_{2}\right]$ (S6, $500 \mathrm{mg}, 0.838 \mathrm{mmol}, 1.00$ equiv) in dry, degassed toluene $(30 \mathrm{~mL})$ in a $100 \mathrm{~mL}$ round-bottom flask was cooled in a cold well with a dry ice/acetone bath. A solution of methyllithium $\left(1.05 \mathrm{~mL}\right.$ of a $1.6 \mathrm{M}$ solution in $\mathrm{Et}_{2} \mathrm{O}$, $1.676 \mathrm{mmol}, 2.00$ equiv) additionally diluted with $3.0 \mathrm{~mL}$ diethyl ether was added dropwise with stirring while the flask was in the cold well. A color change from light green to blue-green was observed. The reaction mixture was stirred for $30 \mathrm{~min}$ in the cold well, removed from the cold well, stirred for $2.5 \mathrm{~h}$ at room temperature, filtered, and concentrated in vacuo to afford catalyst C2 (370 mg, 82\%). as a dark blue/purple solid. This material was used for catalytic reactions without further purification. The ${ }^{1} \mathrm{H}$ NMR spectrum matched that in the literature. ${ }^{5}$

Overall yield: $59 \% \times 55 \% \times 85 \% \times \mathbf{9 8} \% \times \mathbf{8 2} \%=\mathbf{2 2} \%$ over 5 steps 


\section{Synthesis of Olefins}

\section{9-Octadecene (1g)}

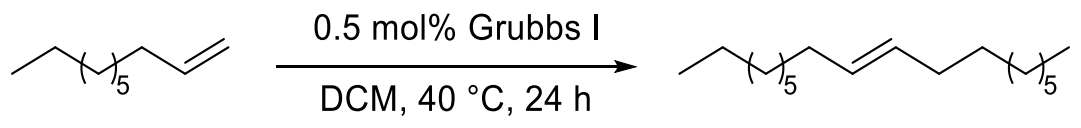

The following procedure for the self-metathesis of 1-decene was adapted from that of Hong and co-workers. ${ }^{8}$ In an argon-filled glovebox, 1-decene $(4.00 \mathrm{~mL}, 21.2 \mathrm{mmol}, 1$ equiv), first-generation Grubbs catalyst $(87.0 \mathrm{mg}, 0.11 \mathrm{mmol}, 0.5 \mathrm{~mol} \%)$, and DCM $(2.80 \mathrm{~mL})$ were added to a $25 \mathrm{~mL}$ flame-dried round-bottom flask. The reaction vessel was connected to an oil bubbler to enable the escape of ethylene, and the reaction mixture was stirred at $40{ }^{\circ} \mathrm{C}$ for 24 hours, cooled to room temperature, and purified by flash column chromatography with isocratic DCM as the eluent. Unreacted 1-decene was removed under high vacuum $\left(50-60{ }^{\circ} \mathrm{C}\right)$ to yield olefin $1 \mathrm{~g}$ as a brown liquid (1.28 g, 48\%). This material was used in catalytic reactions without further purification. The ${ }^{1} \mathrm{H}$ NMR spectrum matched that in the literature. ${ }^{8}$

\section{7-Tetratriacontene $(1 \mathrm{~h})$}

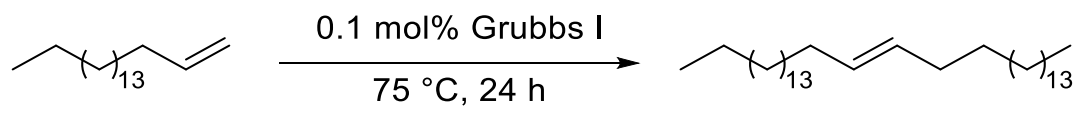

The following procedure for the self-metathesis of 1-octadecene was adapted from that of Inci and co-workers. ${ }^{6}$ In an argon glovebox, 1-octadecene $(3.78 \mathrm{~mL}, 11.8 \mathrm{mmol}, 1$ equiv) and firstgeneration Grubbs catalyst (10 mg, $0.012 \mathrm{mmol}, 0.1 \mathrm{~mol} \%$ ) were added to a $25 \mathrm{~mL}$ flame-dried round-bottom flask. The reaction mixture was stirred at $75^{\circ} \mathrm{C}$ under active vacuum for 24 hours, cooled to room temperature, and quenched with ethyl vinyl ether $(5 \mathrm{~mL})$. The resulting solution was dissolved in toluene $(15 \mathrm{~mL})$ with gentle heating and poured into cold $\mathrm{MeOH}(1 \mathrm{~L})$. The solution was filtered and dried to produce olefin $\mathbf{1 h}$ as a white solid (1.5 g, 53\% yield). The ${ }^{1} \mathrm{H}$ NMR spectrum matched that in the literature. ${ }^{7}$ 


\section{(Z)-((Hex-4-en-1-yloxy)methyl)benzene (1i)}<smiles>C/C=C\CCCOCc1ccccc1</smiles>

Olefin 1i was synthesized according to the literature. ${ }^{9}$

\section{Methyl dodec-10-enoate (S7)}

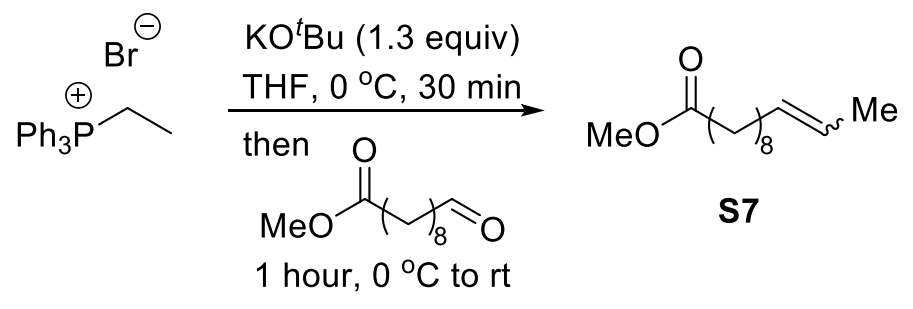

Under nitrogen, ethyl triphenylphosphonium bromide (4.83 g, $13.0 \mathrm{mmol}, 1.3$ equiv) was dissolved in dry THF $(125 \mathrm{~mL})$ in a flame-dried round-bottom flask and cooled to $0{ }^{\circ} \mathrm{C}$. Potassium tert-butoxide ( $1.40 \mathrm{~g} 12.5 \mathrm{mmol}, 1.25$ equiv) was added in one portion. The solution immediately turned bright orange and was stirred at $0^{\circ} \mathrm{C}$ for an additional $30 \mathrm{~min}$. A solution of methyl 9formylnonoate $(2.00 \mathrm{~g}, 10 \mathrm{mmol}, 1.00$ equiv $)$ in dry THF $(10 \mathrm{~mL})$ was added dropwise over $5 \mathrm{~min}$ at $0{ }^{\circ} \mathrm{C}$, and the resulting canary yellow solution was stirred at $0{ }^{\circ} \mathrm{C}$ for an additional 45 minutes, at which point TLC confirmed complete consumption of starting material. The reaction mixture was diluted with diethyl ether $(25 \mathrm{~mL})$ and quenched by adding saturated $\mathrm{NH}_{4} \mathrm{Cl}(50 \mathrm{~mL})$. The organic layer was separated, and the aqueous layer was washed with diethyl ether ( 3 x $25 \mathrm{~mL})$. The combined organic extracts were washed with brine, dried over $\mathrm{Na}_{2} \mathrm{SO}_{4}$, concentrated in vacuo, eluted through a $20 \mathrm{~g}$ silica plug with 5\% EtOAc/hexanes, and concentrated in vacuo to afford $\mathbf{S 7}$ as a colorless oil $(1.95 \mathrm{~g}, 92 \%)$. The product was used without further purification. $\mathrm{R}_{\mathrm{F}}=0.50-0.56$ in $6 \% \mathrm{EtOAc} /$ hexanes. 


\section{$N$-Methoxy- $N$-methyldodec-10-enamide (S8)}

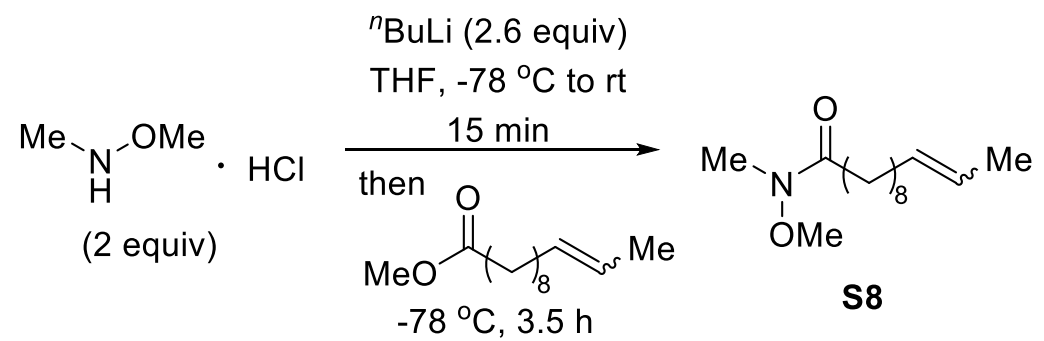

Under nitrogen, $N, O$-dimethylhydroxylamine hydrochloride ( $977 \mathrm{mg}, 16.0 \mathrm{mmol}, 2.00$ equiv) was suspended in dry THF $(9.50 \mathrm{~mL})$ in a flame-dried round-bottom flask and cooled to $-78{ }^{\circ} \mathrm{C} . n$ Butyllithium (2.5 M in hexanes, $6.40 \mathrm{~mL}, 32.0 \mathrm{mmol}, 2.60$ equiv) was added dropwise with stirring to the suspension. The dry ice bath was removed, and the resulting pale-yellow solution was allowed to warm to room temperature for 15 minutes. The solution was cooled again to $-78{ }^{\circ} \mathrm{C}$, and a solution of methyl (E/Z)-dodec-10-enoate (S7, $1.70 \mathrm{~g}, 8.00 \mathrm{mmol}, 1.00$ equiv) in THF (5.00 $\mathrm{mL})$ was added. The solution was stirred for 3.5 hours, diluted with diethyl ether $(10 \mathrm{~mL})$, and quenched with saturated $\mathrm{NH}_{4} \mathrm{Cl}(10 \mathrm{~mL})$. The organic layer was collected, and the aqueous phase was extracted into diethyl ether $(3 \times 25 \mathrm{~mL})$. The combined organic extracts were washed with brine, dried over $\mathrm{Na}_{2} \mathrm{SO}_{4}$, concentrated in vacuo, and purified by flash column chromatography on silica gel (50 g silica 15-20\% ethyl acetate/hexanes) to yield pure $\mathbf{S 8}$ as a colorless oil (1.26 g, $65 \%)$. The product was used without further purification. $\mathrm{R}_{\mathrm{F}}=0.27(20 \%$ EtOAc/hexanes $)$. 


\section{Hexadec-14-en-5-one (S9)}
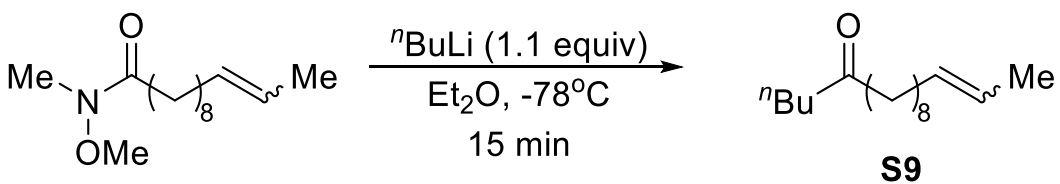

Weinreb amide S8 (483 mg, $2.00 \mathrm{mmol}, 1.00$ equiv) was dissolved in dry diethyl ether (15 mL) and cooled to $-78^{\circ} \mathrm{C}$, and $n$-butyllithium $(2.5 \mathrm{M}$ in hexanes, $880 \mu \mathrm{L}, 2.20 \mathrm{mmol}, 1.10$ equiv) was added dropwise with stirring. The starting material was consumed after $20 \mathrm{~min}$, as indicated by TLC. The reaction was quenched with saturated $\mathrm{NH}_{4} \mathrm{Cl}(10 \mathrm{~mL})$. The organic layer was separated, and the aqueous layer extracted into diethyl ether $(3 \times 10 \mathrm{~mL})$. The combined organic extracts were washed with brine, dried over $\mathrm{Na}_{2} \mathrm{SO}_{4}$, concentrated in vacuo, and purified by flash column chromatography (10 g silica, 10\% ethyl acetate/hexanes) to afford pure $\mathbf{S 9}$ as a colorless oil (468 $\mathrm{mg}, 98 \%$ yield). The product was used without further purification. $\mathrm{R}_{\mathrm{F}}=0.60(10 \%$ EtOAc/hexanes). 


\section{2-Butyl-2-(undec-9-en-1-yl)-1,3-dioxolane (1k)}

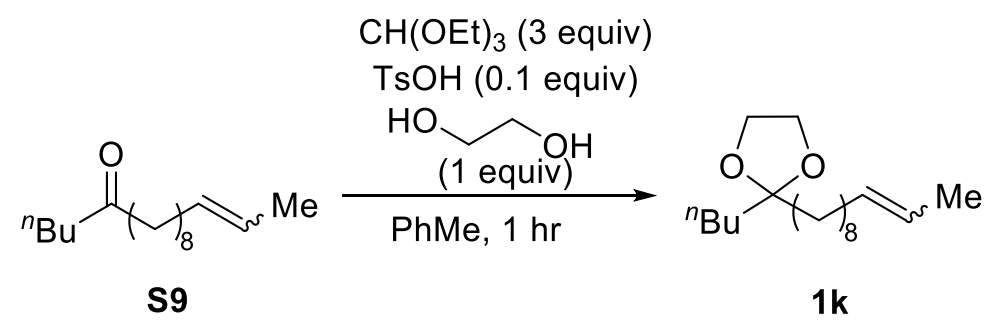

In a round-bottom flask, ketone $\mathbf{S 9}$ (193.5, $0.812 \mathrm{mmol}, 1.00$ equiv) was dissolved in toluene (5 $\mathrm{mL}) . \mathrm{TsOH} \cdot \mathrm{H}_{2} \mathrm{O}(20 \mathrm{mg}, 0.1$ equiv), ethylene glycol (45.4 $\mu \mathrm{L}, 0.812 \mathrm{mmol}, 1.00$ equiv), and triethyl orthoformate (582 $\mu \mathrm{L}, 2.44 \mathrm{mmol}, 3.00$ equiv) were added. The solution was stirred at room temperature for 1 hour, becoming orange-brown in color, and the solvent was removed at $40{ }^{\circ} \mathrm{C}$ with rotary evaporation (note: care was taken to avoid exposure of the product to water, which hydrolyzes the ketal). The reaction mixture was purified by flash column chromatography (dry loaded with $4 \mathrm{~g}$ basic alumina onto a $30 \mathrm{~g}$ silica column, eluted with $10 \% \mathrm{EtOAc} / \mathrm{hexanes}$ ) to afford 4 as a pale-yellow oil (225 mg, 98.3\% yield). The product was used without further purification. $\mathrm{R}_{\mathrm{F}}=0.60(10 \% \mathrm{EtOAc} /$ hexanes; the same as ketone $\mathbf{S 9})$. 


\section{General Procedures for Olefin Isomerizations}

\section{Step 1: Hydroboration}

In an argon-filled glovebox, olefin (dried over anhydrous $\mathrm{MgSO}_{4}$ and sparged with argon for 30 minutes), solvent (640 $\mu \mathrm{L}$, sparged with Argon for $30 \mathrm{~min}$, note: MTBE was added for hydroborations catalyzed by complex $\mathbf{C 1}$, and no solvent was added for hydroborations catalyzed by complex C2), and HBpin (1.05 equiv, SureSeal bottle, sparged with Argon for 30 min) were added to an oven-dried $20 \mathrm{~mL}$ vial equipped with a stir bar. The hydroboration catalyst was then added as a solid with stirring (Note: deviations from this order of addition lead to lower yields. The hydroboration catalyst must be added after olefin and HBpin are already present in the reaction mixture). The reaction mixture was stirred at the specified temperature for the specified reaction time.

\section{Step 2: Dehydroboration}

In an argon-filled glovebox, potassium methoxide $(0.640 \mathrm{mmol}$, prepared by above procedure $)$ and THF $(640 \mu \mathrm{L})$ were added to the reaction mixture, the reaction mixture was stirred for 5 min at room temperature, a solution of iodine $(0.640 \mathrm{mmol})$ in THF $(640 \mu \mathrm{L})$ was added, the reaction mixture was stirred for an additional $5 \mathrm{~min}$ at room temperature, a solution of potassium tertbutoxide $(0.320 \mathrm{mmol})$ in THF $(320 \mu \mathrm{L})$ was added, and the reaction was stirred for a third 5 minute period at room temperature. This procedure of sequentially adding KOMe and THF, a solution of $\mathrm{I}_{2}$ in THF, and a solution of $\mathrm{KO} t \mathrm{Bu}$ in THF was repeated 3-4 times, as specified for each reaction. After the addition of each reagent, the vial was shaken vigorously. Potassium tertbutoxide (5-6 equiv, as specified for each reaction) and THF $(1280 \mu \mathrm{L})$ were added for the elimination, and the reaction was stirred at room temperature for $20 \mathrm{~h}$ at room temperature. The reaction mixture was diluted with $\mathrm{CDCl}_{3}(15 \mathrm{~mL}$, dropwise addition with rapid stirring), and trichloroethylene $(57.5 \mu \mathrm{L}, 0.640 \mathrm{mmol}, 1.00$ equiv) was added. The reaction mixture was vigorously shaken, an aliquot was filtered, and a crude ${ }^{1} \mathrm{H}$ NMR spectrum was recorded. 


\section{Isomerization of Olefins}

1-Octene $(1 \mathrm{c} \rightarrow 4 \mathrm{c})$

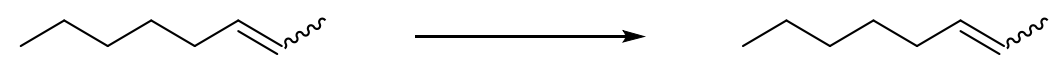

Prepared from 2-octene (mixture of $E$ and $Z$ isomers, $99.8 \mu \mathrm{L}, 0.640 \mathrm{mmol}$ ) according to the general procedure with catalyst $\mathbf{C 1}(6.5 \mathrm{mg}, 2 \mathrm{~mol} \%)$ as the hydroboration catalyst. The hydroboration was conducted at room temperature for $24 \mathrm{~h}$. The iodination was conducted with 3 additions of $\mathrm{KOMe}, \mathrm{I}_{2}$, and $\mathrm{KO}(t-\mathrm{Bu})$ before the final elimination with 5 equiv $\mathrm{KO}(t-\mathrm{Bu})$. ${ }^{1} \mathrm{H}$ NMR Yield: $82 \%$, no isomers detected

\section{1-Octene $(1 \mathrm{~d} \rightarrow 4 \mathrm{c})$}

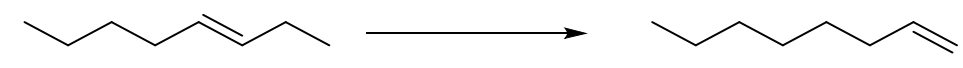

Prepared from $(E)-3$-octene $(100.3 \mu \mathrm{L}, 0.640 \mathrm{mmol})$ according to the general procedure with catalyst $\mathbf{C 1}$ (6.5 mg, $2 \mathrm{~mol} \%$ ) as the hydroboration catalyst. The hydroboration was conducted at room temperature for $24 \mathrm{~h}$. The iodination was conducted with 3 additions of $\mathrm{KOMe}, \mathrm{I}_{2}$, and $\mathrm{KO}(t$ $\mathrm{Bu})$ before the final elimination with 5 equiv $\mathrm{KO}(t-\mathrm{Bu})$.

${ }^{1} \mathrm{H}$ NMR Yield: $77 \%$, no isomers detected

\section{1-Octene $(1 \mathrm{e} \rightarrow 4 \mathrm{c})$}

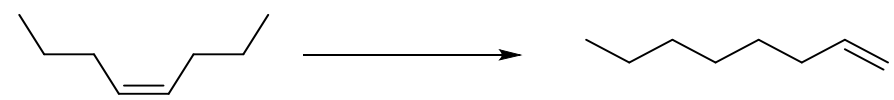

Prepared from cis-4-octene $(99.9 \mu \mathrm{L}, 0.640 \mathrm{mmol}$, olefin 1e) according to the general procedure with catalyst $\mathbf{C 1}(6.5 \mathrm{mg}, 2 \mathrm{~mol} \%)$ as the hydroboration catalyst. The hydroboration was conducted at room temperature for $24 \mathrm{~h}$. The iodination was conducted with 3 additions of $\mathrm{KOMe}, \mathrm{I}_{2}$, and $\mathrm{KO}(t-\mathrm{Bu})$ before the final elimination with 5 equiv $\mathrm{KO}(t-\mathrm{Bu})$.

${ }^{1} \mathrm{H}$ NMR Yield: $51 \%$, no isomers detected 


\section{1-Tetradecene $(\mathbf{1 f} \rightarrow$ 4f $)$}

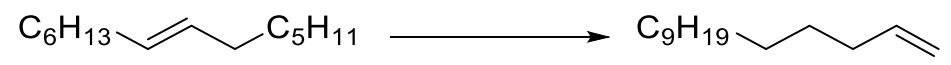

Prepared from trans-7-tetradecene $(164.5 \mu \mathrm{L}, 0.640 \mathrm{mmol})$ according to the general procedure with catalyst $\mathbf{C 1}(8.1 \mathrm{mg}, 5.0 \mathrm{~mol} \%)$ as the hydroboration catalyst. The hydroboration was conducted at room temperature for $24 \mathrm{~h}$. The iodination was conducted with 3 additions of KOMe, $\mathrm{I}_{2}$, and $\mathrm{KO}(t-\mathrm{Bu})$ before the final elimination with 5 equiv $\mathrm{KO}(t-\mathrm{Bu})$.

${ }^{1} \mathrm{H}$ NMR Yield: 81\%, 99:1 terminal: internal

Isolation of Olefin 4f: The NMR sample and crude reaction mixture were combined and carefully diluted with water $(100 \mathrm{~mL})$, and the resulting mixture was extracted with pentane $(3 \mathrm{x} 100 \mathrm{~mL})$. The pentane layer was washed with $2 \mathrm{M}$ sodium thiosulfate $(3 \times 100 \mathrm{~mL})$ and brine $(1 \times 150 \mathrm{~mL})$, dried over sodium sulfate, and carefully concentrated in vacuo to afford a pale-yellow liquid. Column chromatography on silica gel $(60 \mathrm{~g})$ with isocratic pentane followed by careful concentration in vacuo afforded pure 1-tetradecene as a clear oil $\left(85.5 \mathrm{mg}, 68 \%\right.$ isolated yield). ${ }^{1} \mathrm{H}$ NMR (400 MHz, Chloroform- $d$ ) $\delta 5.86(\mathrm{ddt}, J=16.9,10.2,6.7 \mathrm{~Hz}, 1 \mathrm{H}), 5.04$ (dq, $J=17.1,1.8$ $\mathrm{Hz}, 1 \mathrm{H}), 4.97$ (dq, $J=10.2,1.4 \mathrm{~Hz}, 1 \mathrm{H}), 2.08$ (tdd, $J=8.0,6.1,1.5 \mathrm{~Hz}, 2 \mathrm{H}), 1.30$ (s, 17H), 0.92 (t, $J=6.8 \mathrm{~Hz}, 3 \mathrm{H})$.

\section{1-Octadecene $(1 \mathrm{~g} \rightarrow 4 \mathrm{~g})$}

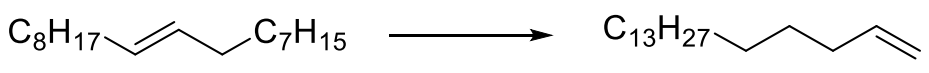

Prepared from 9-octadecene $(80.8 \mathrm{mg}, 0.320 \mathrm{mmol})$ according to the general procedure with catalyst C1 (10.4 mg, $3 \mathrm{~mol} \%$ ) as the hydroboration catalyst. The hydroboration was conducted at room temperature for $24 \mathrm{~h}$. The iodination was conducted with 3 additions of $\mathrm{KOMe}, \mathrm{I}_{2}$, and $\mathrm{KO}(t$ $\mathrm{Bu})$ before the final elimination with 5 equiv $\mathrm{KO}(t-\mathrm{Bu})$.

${ }^{1} \mathrm{H}$ NMR Yield: 66\%, 96:4 terminal:internal 


\section{1-Tetratriacontene $(1 \mathrm{~h} \rightarrow 4 \mathrm{~h})$}

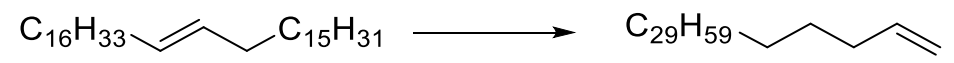

Prepared from 17-tetratriacontene $(305.2 \mathrm{mg}, 0.640 \mathrm{mmol})$ according to the general procedure with catalyst $\mathbf{C 1}(16.1 \mathrm{mg}, 5 \mathrm{~mol} \%$ ) as the hydroboration catalyst. The hydroboration was conducted at $65^{\circ} \mathrm{C}$ for $24 \mathrm{~h}$. The iodination was at $65^{\circ} \mathrm{C}$ conducted with 3 additions of KOMe, $\mathrm{I}_{2}$, and $\mathrm{KO}(t-\mathrm{Bu})$ before the final elimination, which was conducted at $65^{\circ} \mathrm{C}$, with 5 equiv $\mathrm{KO}(t$-Bu). ${ }^{1} \mathrm{H}$ NMR Yield: 4\%, 36:64 terminal:internal

\section{((Hex-5-en-1-yloxy)methyl)benzene $(1 \mathrm{i} \rightarrow 4 \mathrm{i})$}

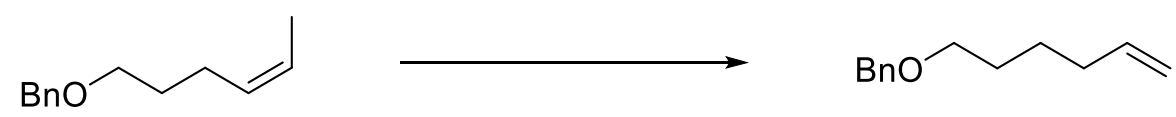

Prepared from (Z)-((hex-4-en-1-yloxy)methyl)benzene ${ }^{9}(85.8 \mu \mathrm{L}, 0.640 \mathrm{mmol})$ according to the general procedure with catalyst C1 $(10.4 \mathrm{mg}, 3 \mathrm{~mol} \%)$ as the hydroboration catalyst. The hydroboration was conducted at room temperature for $72 \mathrm{~h}$. The iodination was conducted with 3 additions of $\mathrm{KOMe}, \mathrm{I}_{2}$, and $\mathrm{KO}(t-\mathrm{Bu})$ before the final elimination with 5 equiv $\mathrm{KO}(t-\mathrm{Bu})$.

${ }^{1} \mathrm{H}$ NMR Yield: 64\%, 77:23 terminal:internal

Isolation of Olefin 4i: The NMR sample and crude reaction mixture were combined and carefully diluted with water $(100 \mathrm{~mL})$, and the resulting mixture was extracted with pentane $(3 \mathrm{x} 100 \mathrm{~mL})$. The pentane layer was washed with $2 \mathrm{M}$ sodium thiosulfate $(3 \times 100 \mathrm{~mL})$ and brine $(1 \times 150 \mathrm{~mL})$, dried over sodium sulfate, and carefully concentrated in vacuo to afford a pale-yellow liquid. Column chromatography on silica gel ( $60 \mathrm{~g}$ ) with a gradient of $0 \rightarrow 5 \%$ ether/pentane followed by careful concentration in vacuo afforded olefin $\mathrm{XX}$ as a clear oil (95.4 mg, 77:23 mixture of terminal:internal olefins, 60\% yield of terminal olefin). ${ }^{1} \mathrm{H}$ NMR (400 MHz, Chloroform- $d$ ) $\delta 7.41$ - 7.37 (m, 1H), 5.85 (ddt, $J=16.9,10.2,6.7 \mathrm{~Hz}, 0 \mathrm{H}), 5.05$ (dq, $J=17.1,1.7 \mathrm{~Hz}, 0 \mathrm{H}), 4.99$ (ddt, $J$ $=10.2,2.2,1.2 \mathrm{~Hz}, 0 \mathrm{H}), 4.55(\mathrm{~s}, 0 \mathrm{H}), 3.60-3.48(\mathrm{~m}, 1 \mathrm{H}), 2.17-2.06(\mathrm{~m}, 0 \mathrm{H}), 1.80-1.59(\mathrm{~m}$, $1 \mathrm{H})$. 
Vinylcyclohexane $(1 \mathbf{j} \rightarrow 4 \mathbf{j})$

$\longrightarrow \longrightarrow$

Prepared from ethylidene cyclohexane $(85.8 \mu \mathrm{L}, 0.640 \mathrm{mmol})$ according to the general procedure with catalyst $\mathbf{C 2}(10.4 \mathrm{mg}, 3 \mathrm{~mol} \%)$ as the hydroboration catalyst. The hydroboration was conducted at room temperature for $24 \mathrm{~h}$. The iodination was conducted with 4 additions of KOMe, $\mathrm{I}_{2}$, and $\mathrm{KO}(t-\mathrm{Bu})$ before the final elimination with 6 equiv $\mathrm{KO}(t-\mathrm{Bu})$.

${ }^{1} \mathrm{H}$ NMR Yield: $56 \%$, no isomers detected

\section{2-Butyl-2-(undec-10-en-1-yl)-1,3-dioxolane $(1 \mathrm{k} \rightarrow 4 \mathrm{k})$}

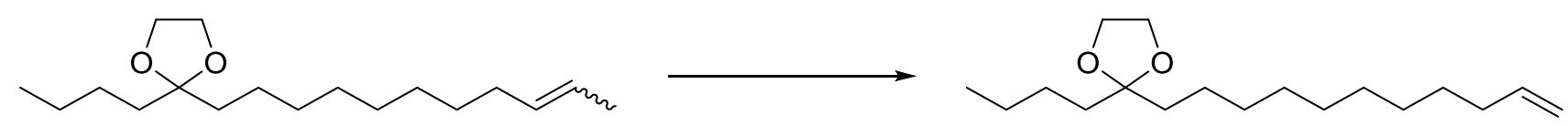

Prepared from 2-butyl-2-(undec-9-en-1-yl)-1,3-dioxolane (90.4 $\mathrm{mg}, 0.320 \mathrm{mmol}$ ) according to the general procedure with catalyst $\mathbf{C 2}(12.1 \mathrm{mg}, 7.0 \mathrm{~mol} \%)$ as the hydroboration catalyst. The hydroboration was conducted at $50{ }^{\circ} \mathrm{C}$ for $96 \mathrm{~h}$. The iodination was conducted with 3 additions of $\mathrm{KOMe}, \mathrm{I}_{2}$, and $\mathrm{KO}(t-\mathrm{Bu})$ before the final elimination with 5 equiv $\mathrm{KO}(t-\mathrm{Bu})$.

${ }^{1} \mathrm{H}$ NMR Yield: 68\%, 86:14 terminal:internal

Isolation of Olefin 4k: The NMR sample and crude reaction mixture were combined and carefully diluted with water $(100 \mathrm{~mL})$, and the resulting mixture was extracted with pentane $(3 \mathrm{x} 100 \mathrm{~mL})$. The pentane layer was washed with $2 \mathrm{M}$ sodium thiosulfate $(3 \times 100 \mathrm{~mL})$ and brine $(1 \times 150 \mathrm{~mL})$, dried over sodium sulfate, and carefully concentrated in vacuo to afford a pale-yellow liquid. Column chromatography on silica gel (60 g) with a gradient of $0 \rightarrow 15 \%$ ether/pentane followed by careful concentration in vacuo afforded olefin $4 \mathbf{k}$ as a yellow oil (62.3 $\mathrm{mg}$, 86:14 mixture of terminal:internal olefins, 59\% yield of terminal olefin). ${ }^{1} \mathrm{H}$ NMR (500 MHz, Chloroform- $d$ ) $\delta 4.99$ $(\mathrm{d}, J=17.1 \mathrm{~Hz}, 1 \mathrm{H}), 4.92$ (d, $J=10.3 \mathrm{~Hz}, 1 \mathrm{H}), 3.92$ (s, 5H), 2.03 (m, $J=7.2 \mathrm{~Hz}, 2 \mathrm{H}), 1.59$ (dt, $J$ $=11.9,4.1 \mathrm{~Hz}, 5 \mathrm{H}), 1.40-1.24(\mathrm{~m}, 26 \mathrm{H}), 0.89(\mathrm{~m}, J=5.6,4.2 \mathrm{~Hz}, 5 \mathrm{H}) .{ }^{13} \mathrm{C} \mathrm{NMR}(151 \mathrm{MHz}$, $\left.\mathrm{CDCl}_{3}\right) \delta 139.3,114.1,111.9,64.9$, 37.2, 36.9, 33.8. 29.6, 29.5, 29.1, 29.0, 26.0, 23.9, 23.0, 14.1. HRMS (EI): $\mathrm{m} / \mathrm{z}$ for $\mathrm{C}_{18} \mathrm{H}_{34} \mathrm{O}_{2}{ }^{+}[\mathrm{M}]+$ calcd. for $\mathrm{C}_{18} \mathrm{H}_{34} \mathrm{O}_{2}{ }^{+}:$282.2553, found: 282.2552. 


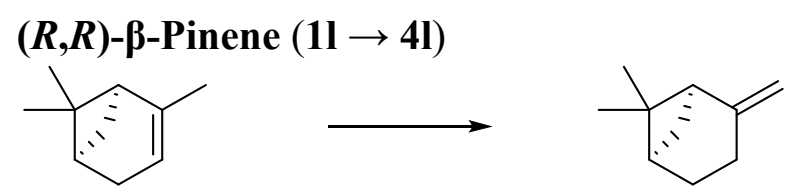

Prepared from $(+)$ - $\alpha$-pinene $(43.6 \mathrm{mg}, 0.320 \mathrm{mmol})$ according to the general procedure with catalyst C2 (12.1 mg, $7.0 \mathrm{~mol} \%$ ) as the hydroboration catalyst. The hydroboration was conducted at $50{ }^{\circ} \mathrm{C}$ for $168 \mathrm{~h}$, and the reaction mixture was cooled to room temperature, eluted through a silica plug with dichloromethane, and concentrated. The iodination was conducted with 3 additions of $\mathrm{KOMe}, \mathrm{I}_{2}$, and $\mathrm{KO}(t$-Bu) before the final elimination with 5 equiv $\mathrm{KO}(t-\mathrm{Bu})$.

${ }^{1} \mathrm{H}$ NMR Yield: 26\%, 75:25 terminal:internal 


\section{NMR Spectra of Olefin Isomerizations}

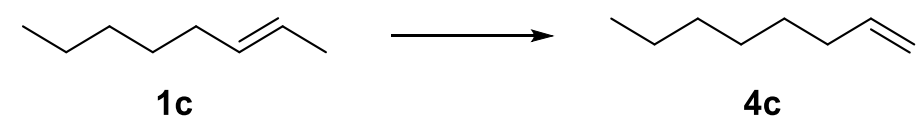

Full spectrum (crude):

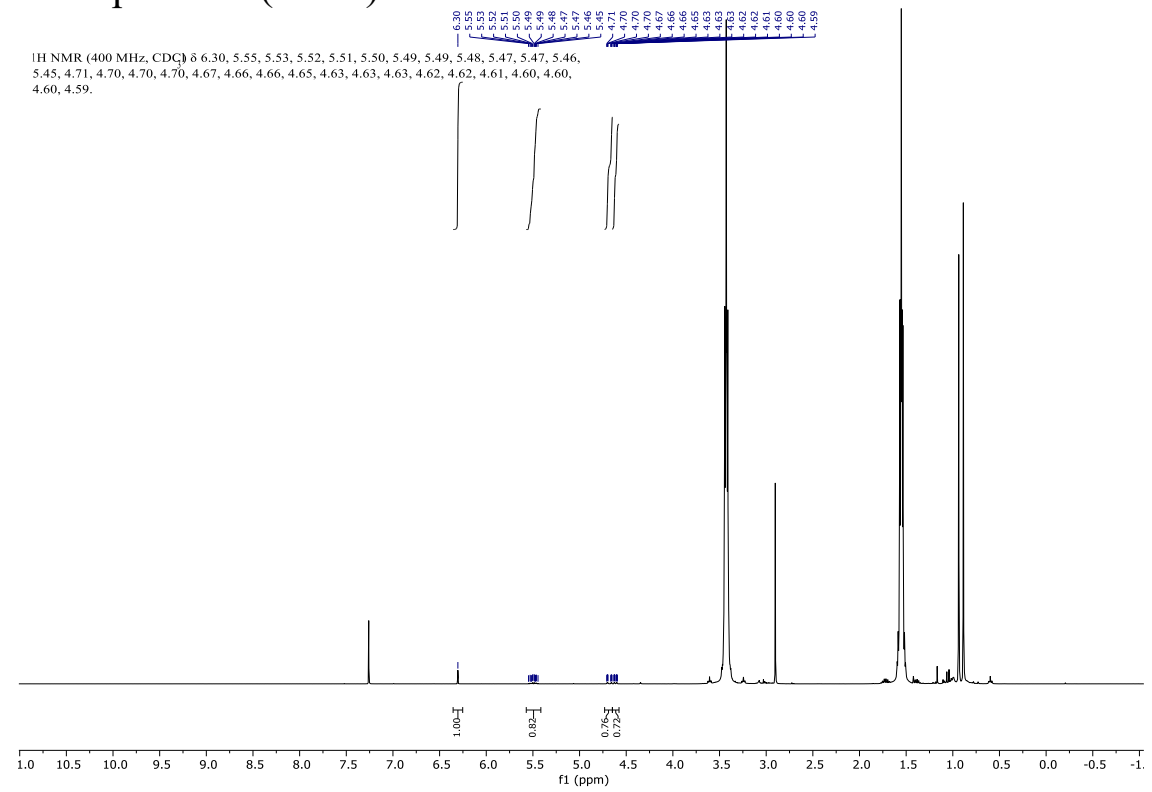

Full spectrum, zoomed up:

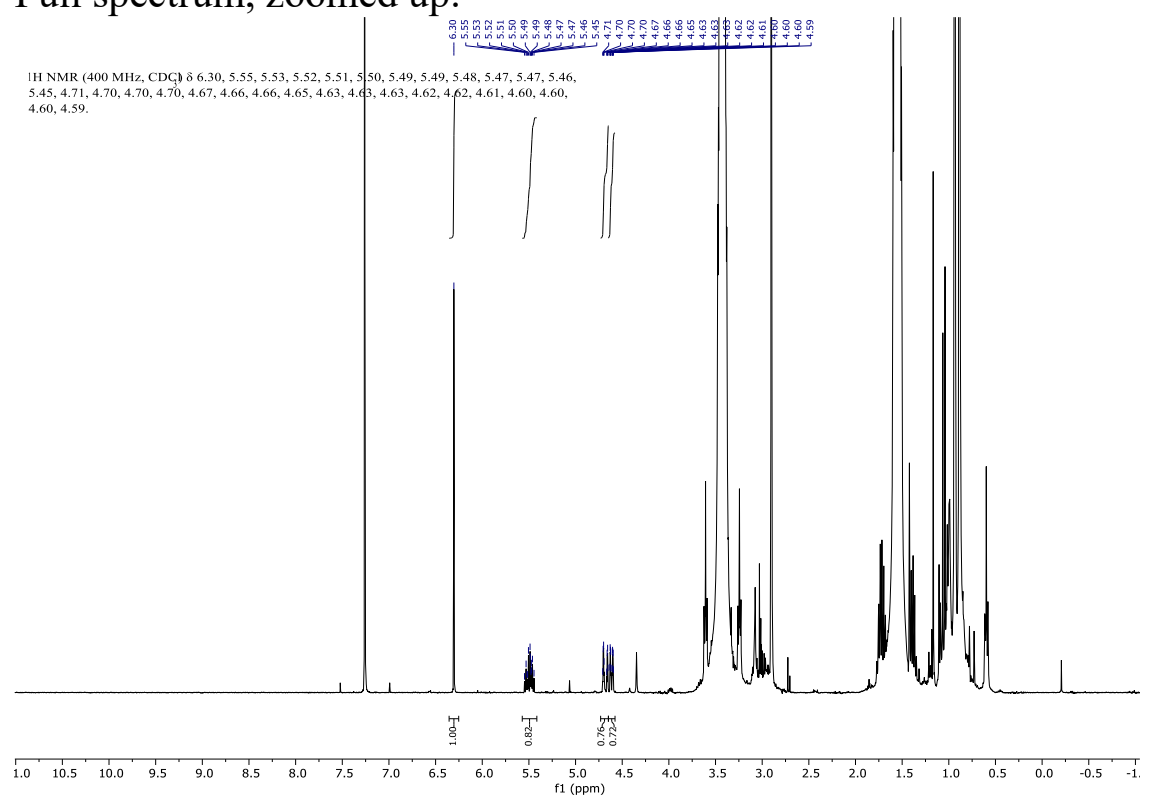




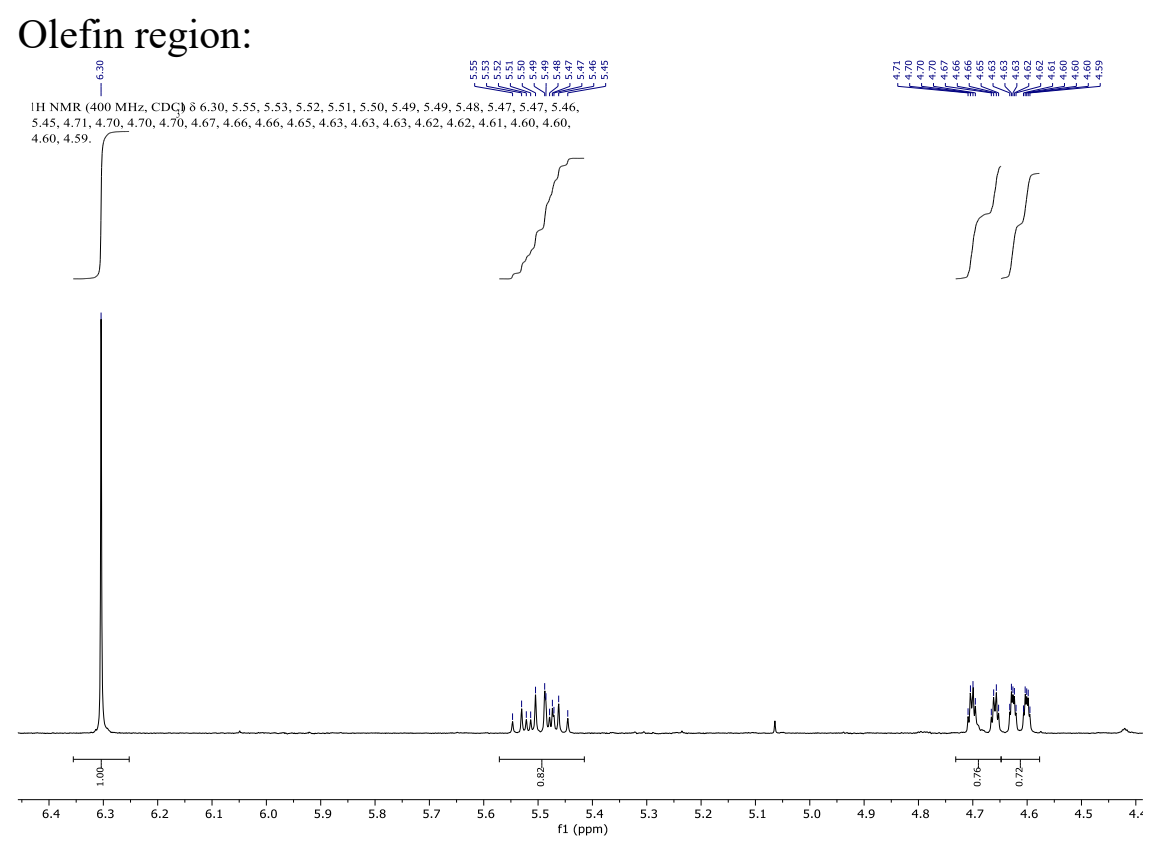




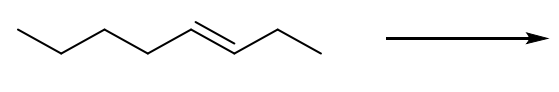

1d

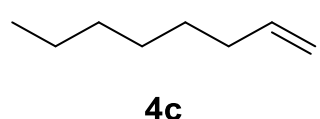

4c

Full spectrum (crude):

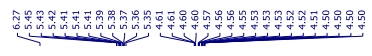

IH NMR (400 MHz, CDG) 8 6.27, 5.45, 5.43, 5.42, 5.41, 5.41, 5.41, 5.39, 5.38, 5.37, 5.36, 5.3.5,

4.50. $4.61,4.60,4.60,4.57,4.56,4.56,4.55,4.53,4.53,4.53,4.52,4.52,4.51,4.50,4.50,4.50$,

$\iint$

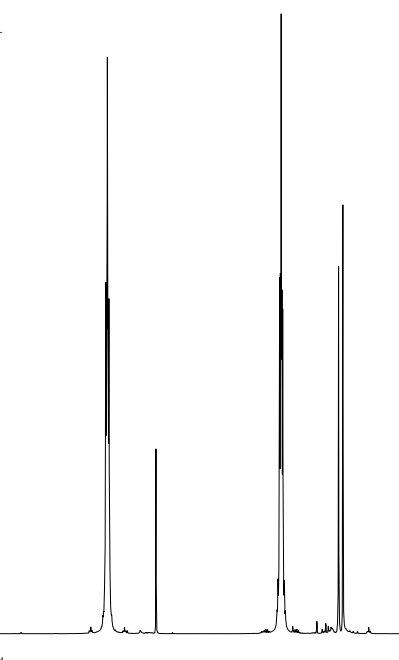

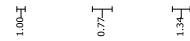

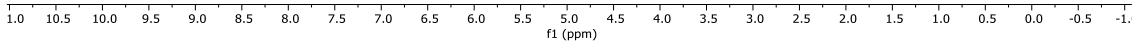

Full spectrum, zoomed up:

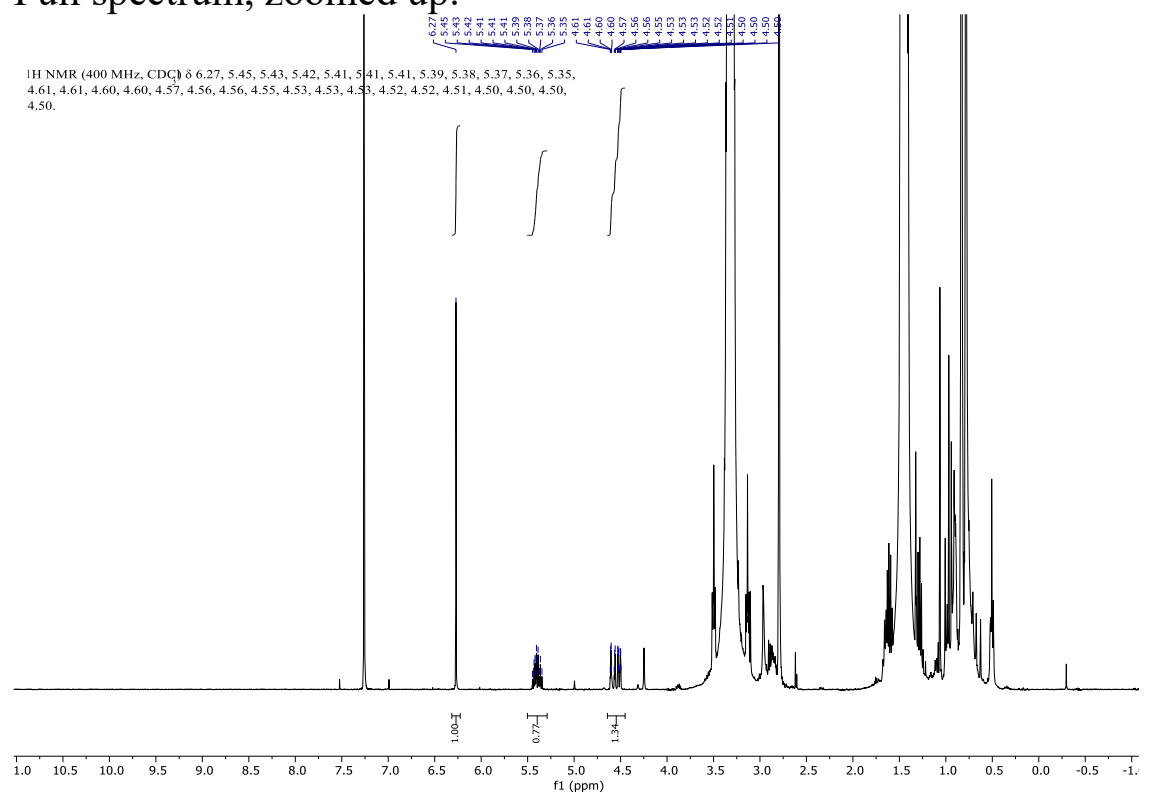


Olefin region:

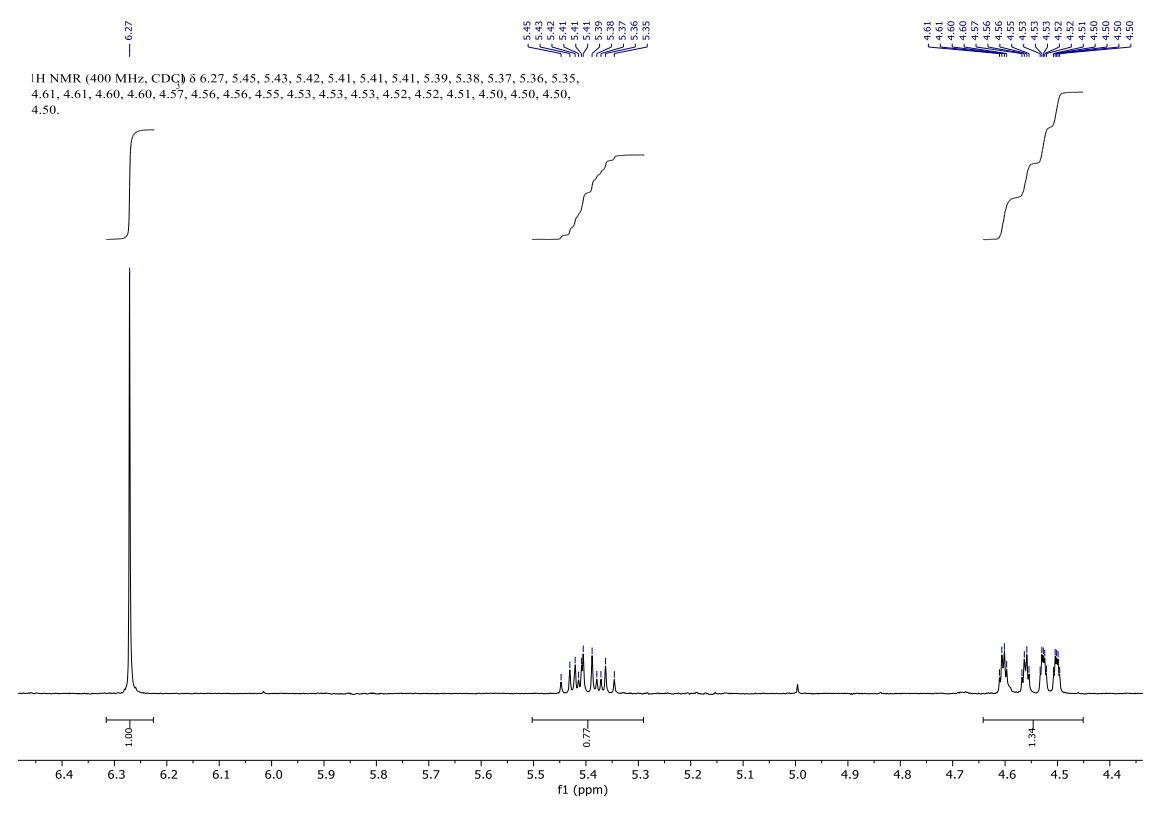




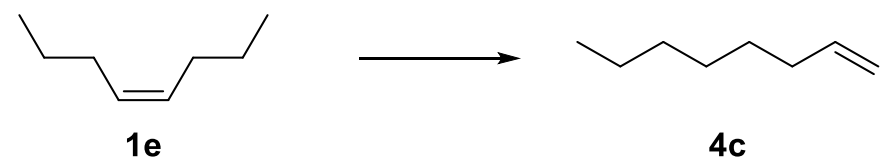

Full spectrum (crude):

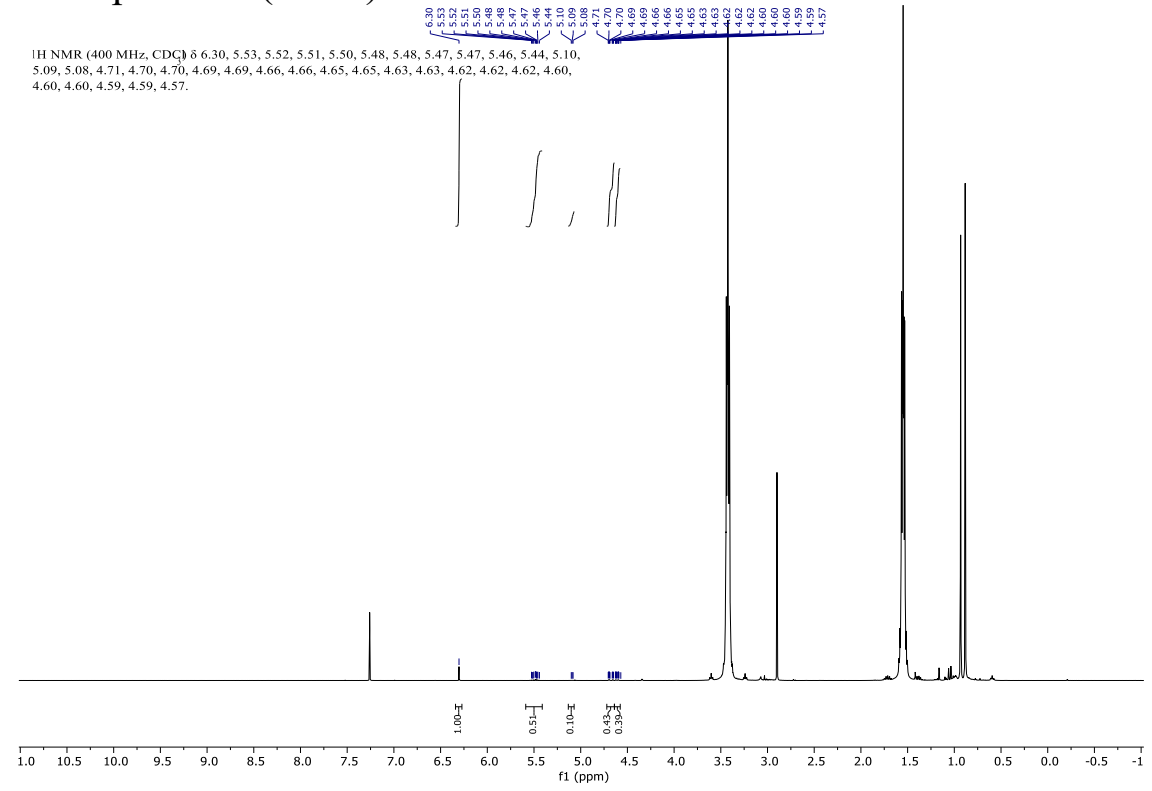

Full spectrum, zoomed up:

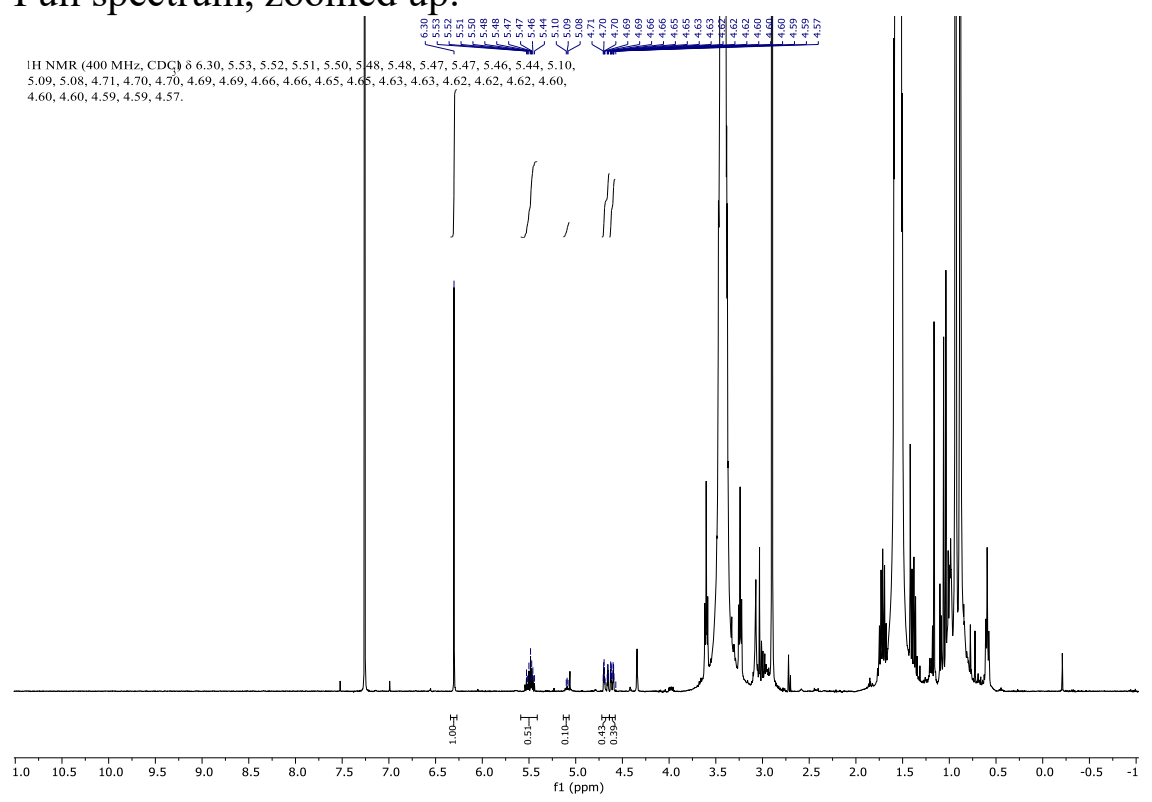


Olefins region:

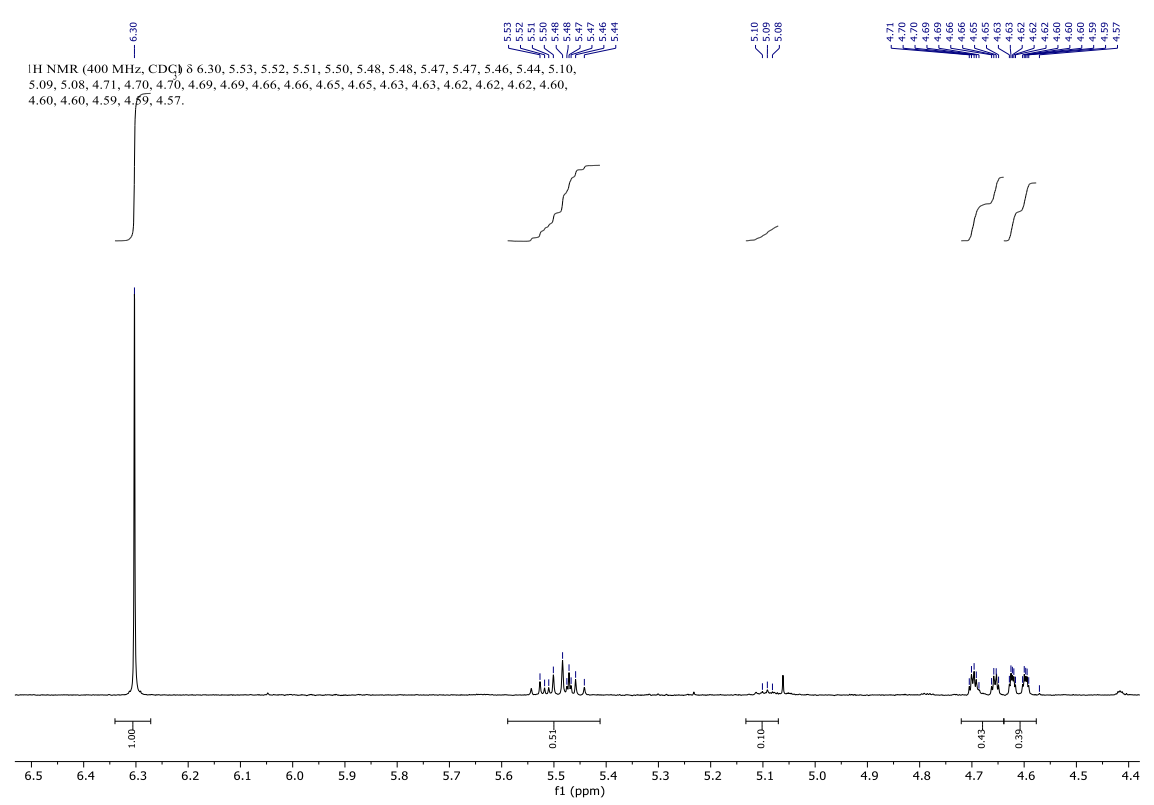




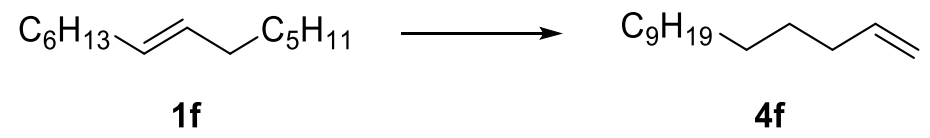

Full spectrum (crude):

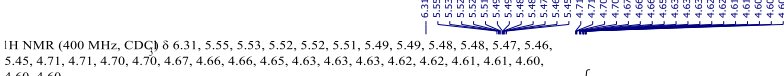

4.60, 4.60.

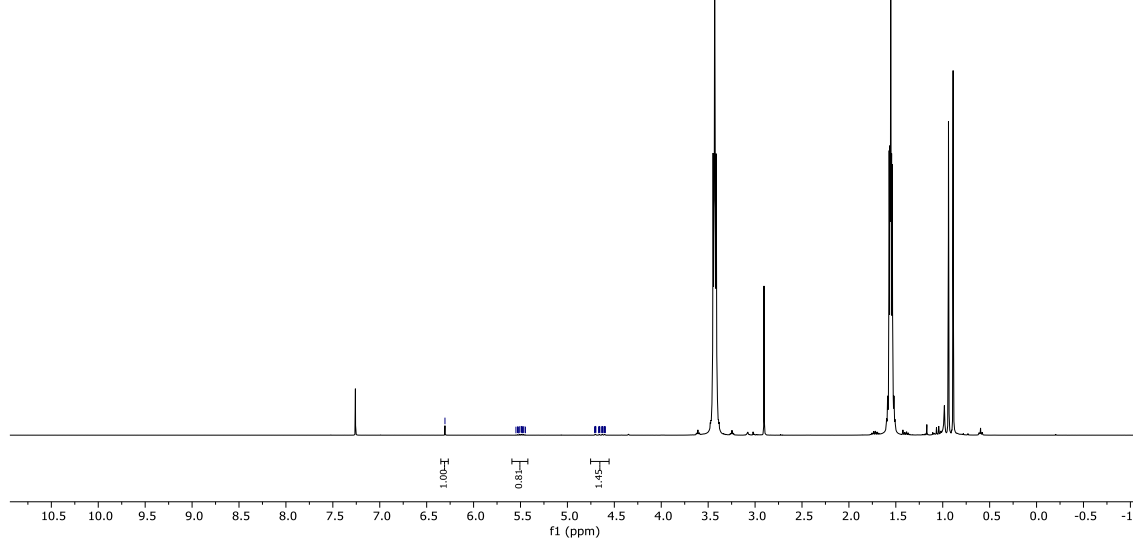

Full spectrum, zoomed up:

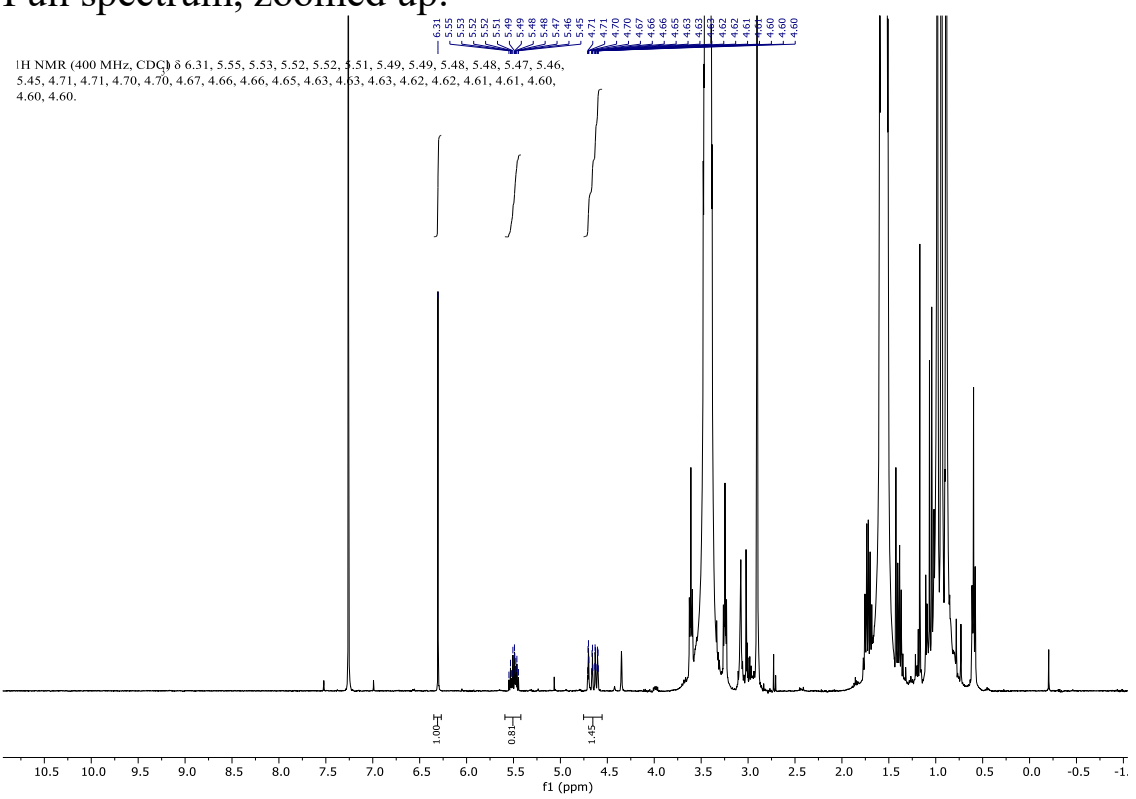


Olefins region:

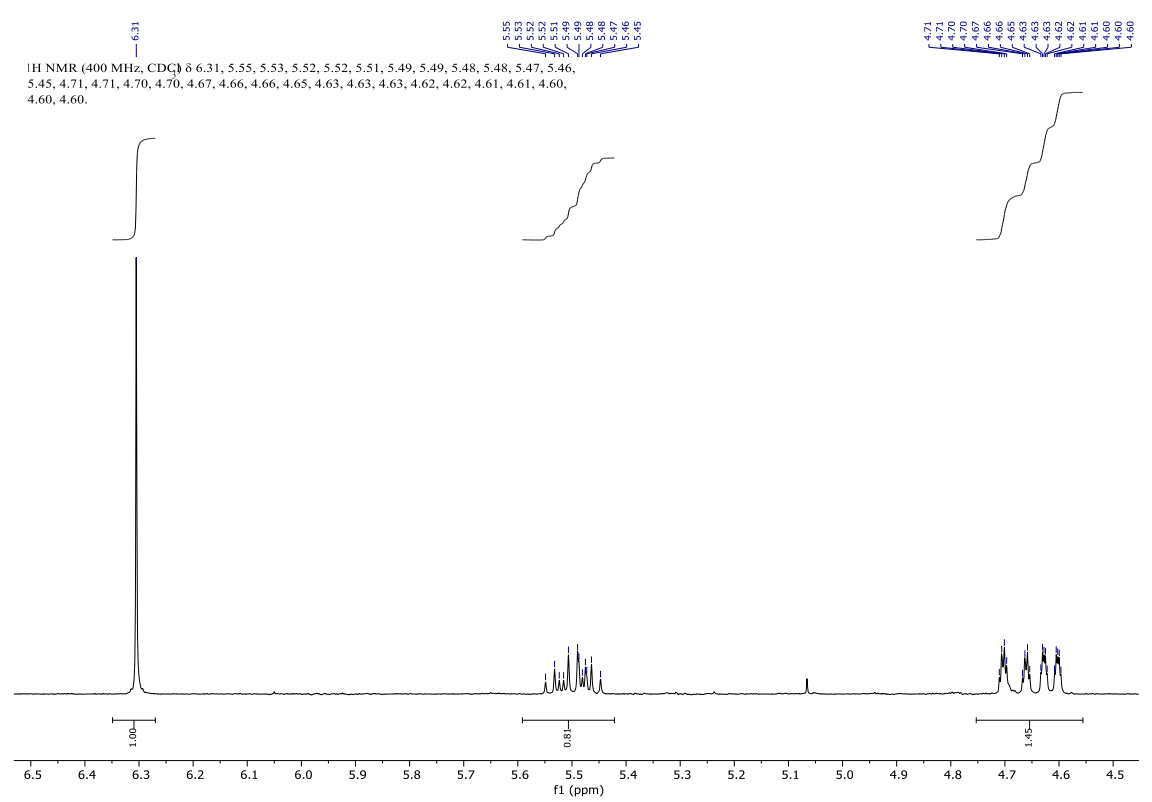


Isolation of Olefin $\mathbf{4 f}$ :

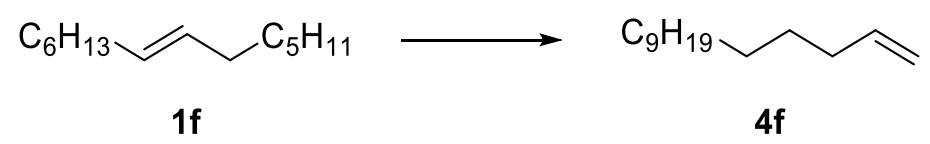

Full spectrum:

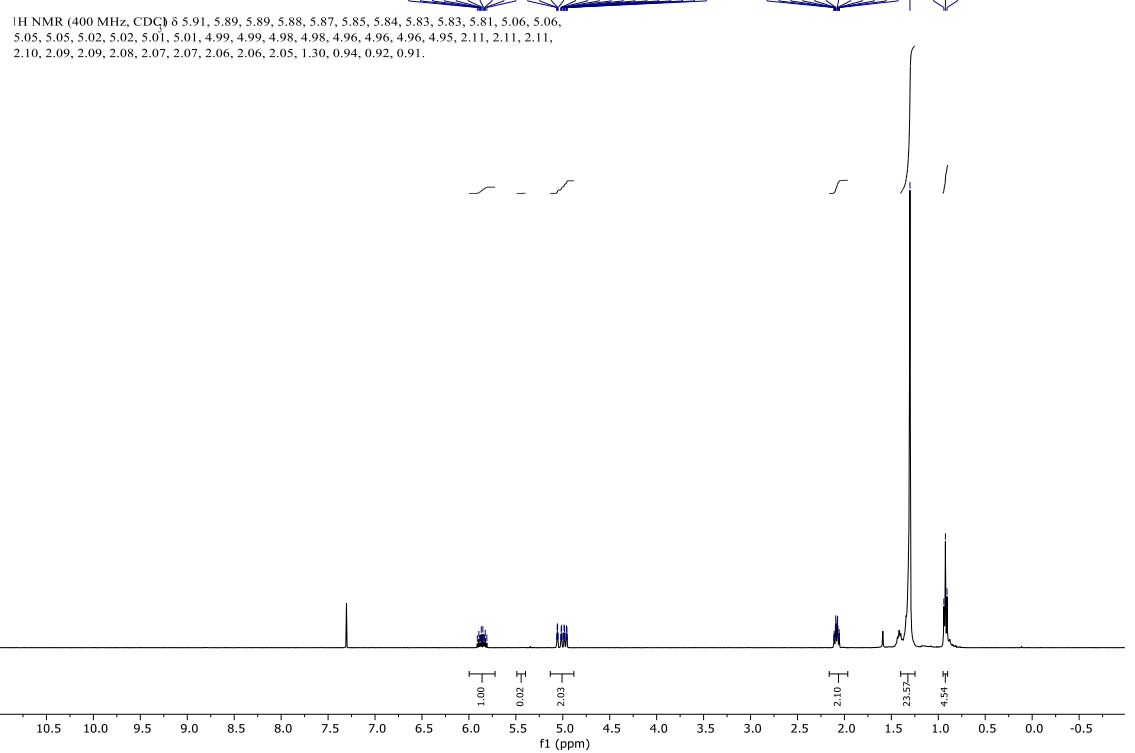

Olefins region:

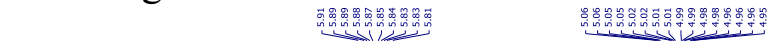

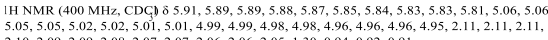

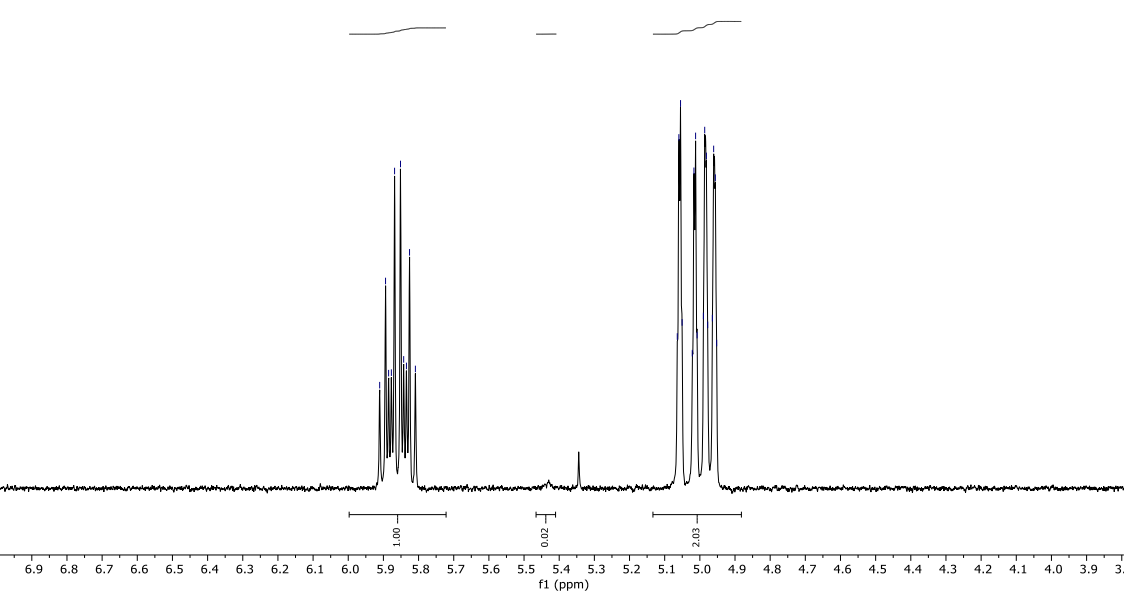




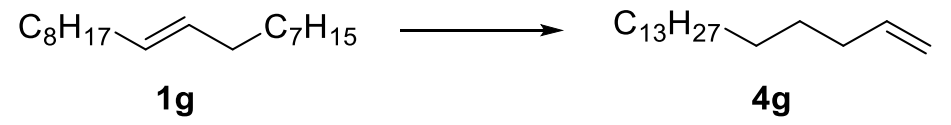

Full spectrum (crude):

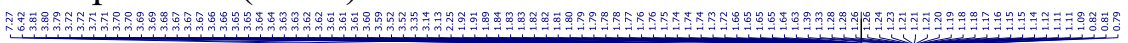

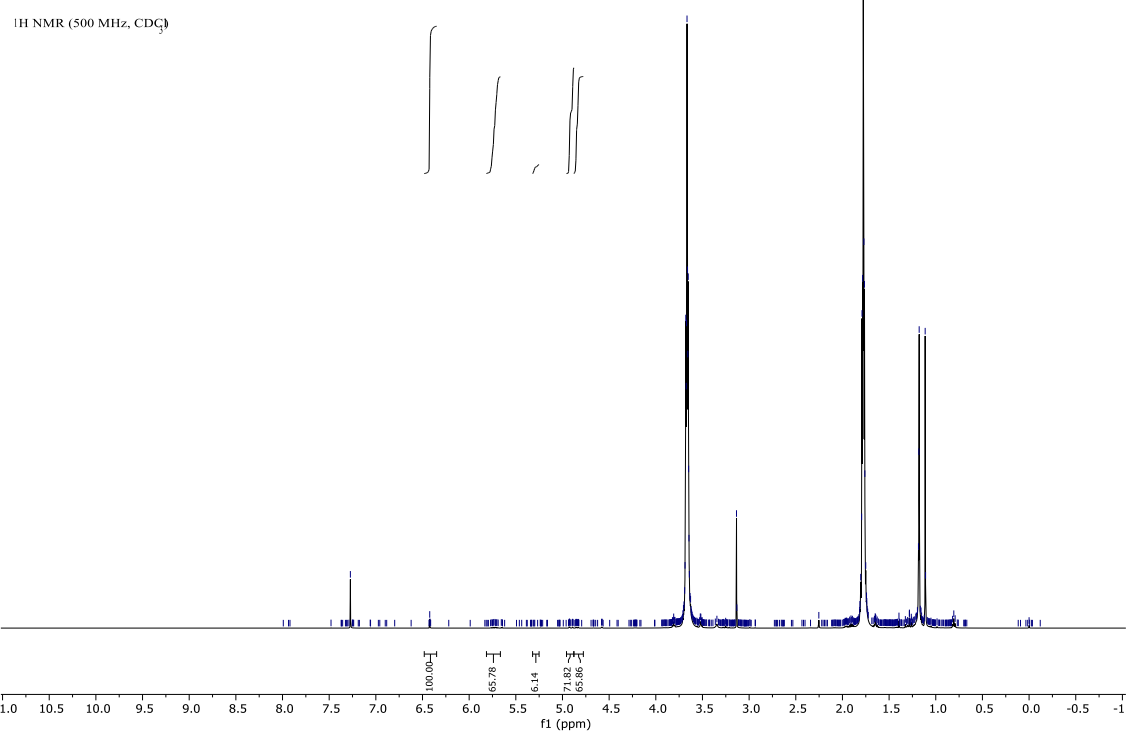

Full spectrum, zoomed up:

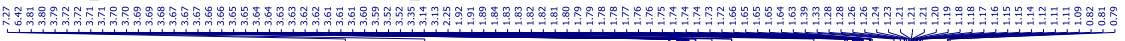

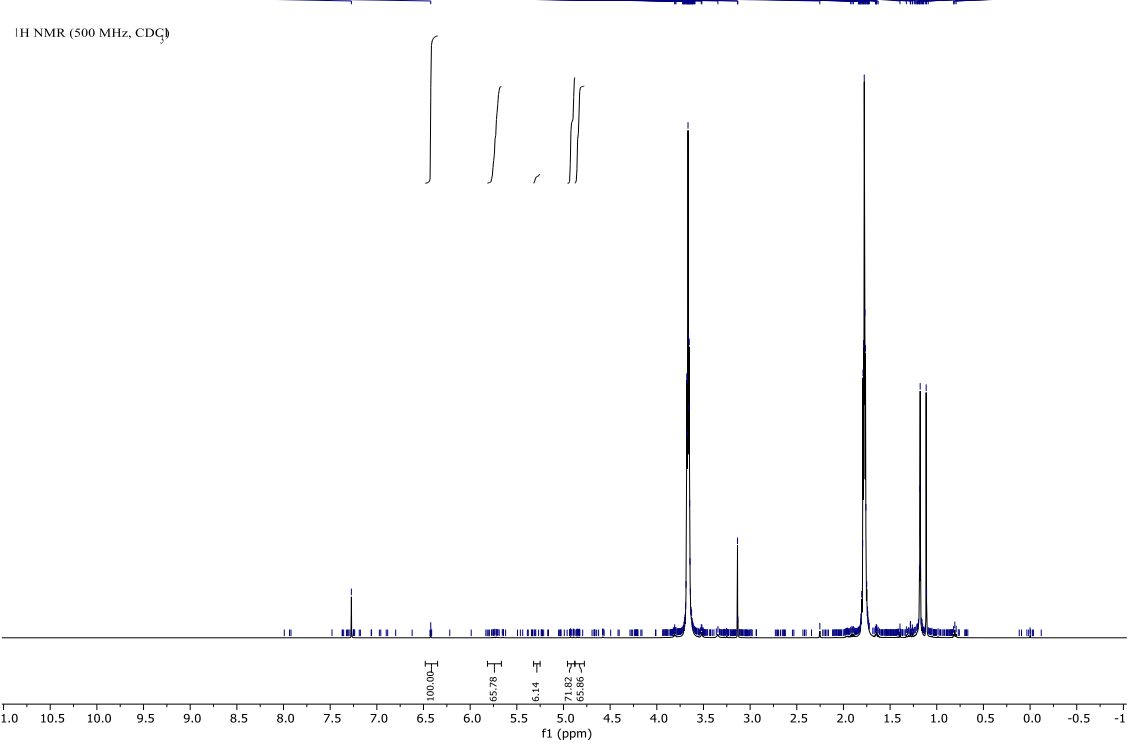


Olefins region:

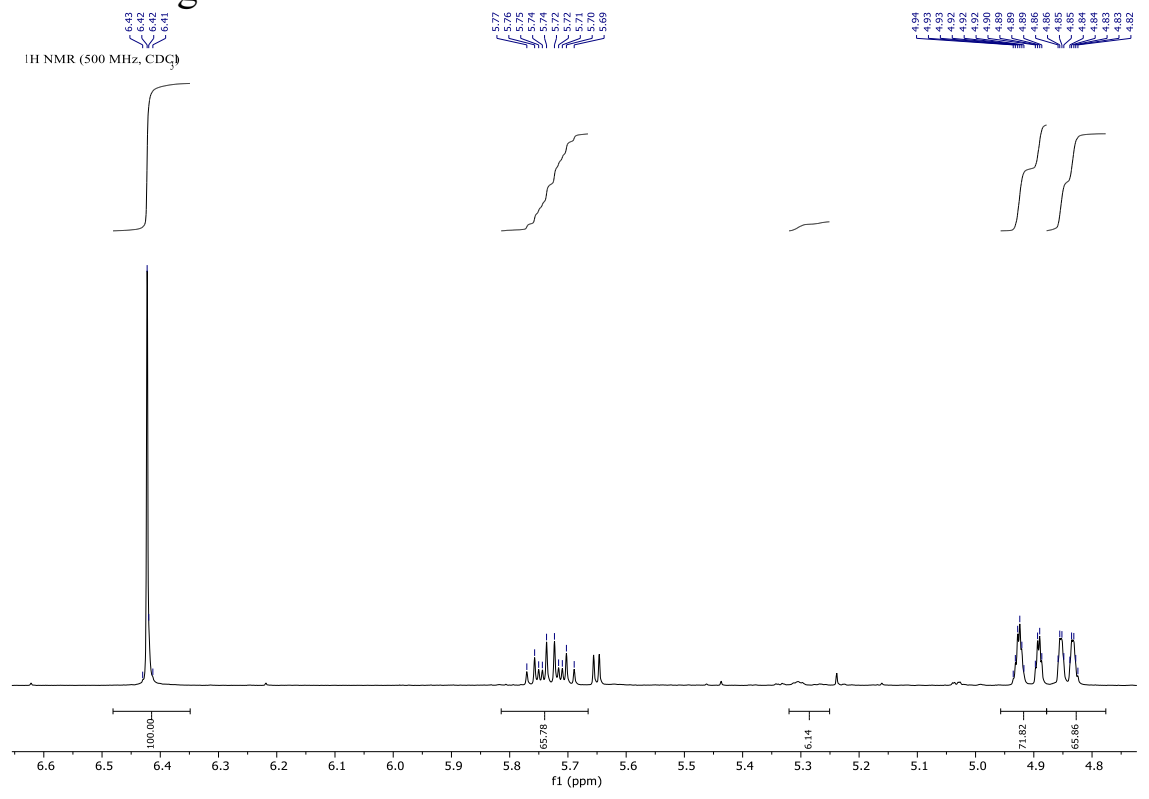




\section{Isolation of Olefin $\mathbf{4 g}$ :}

Full spectrum:

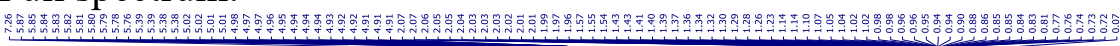

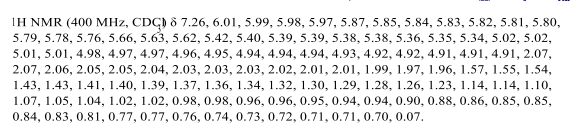

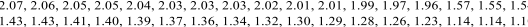

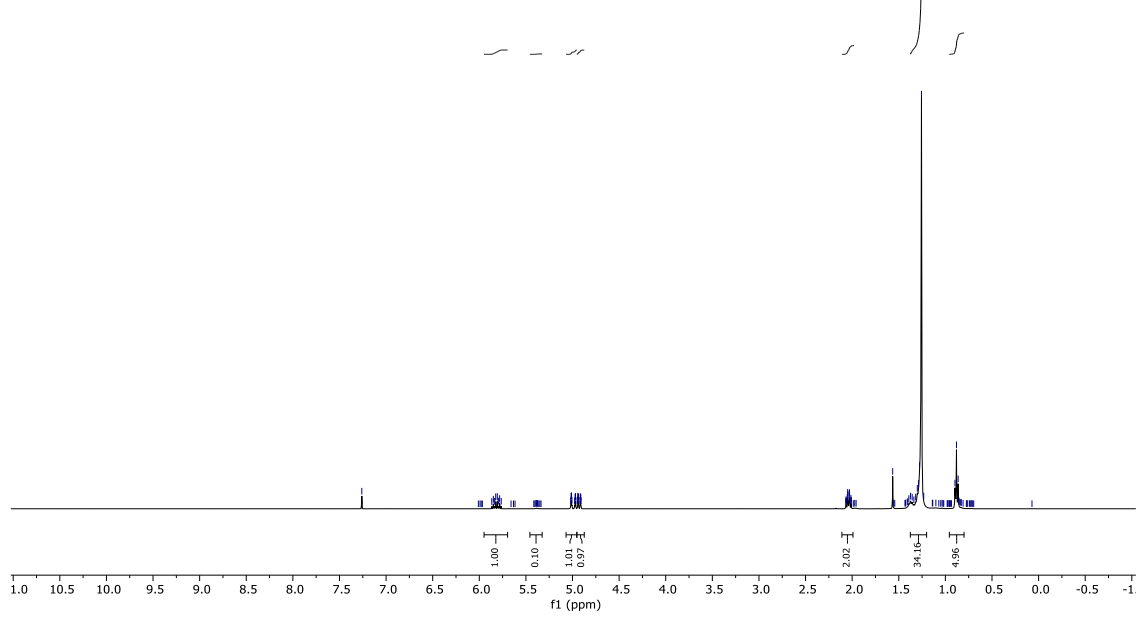

\section{Olefins region:}

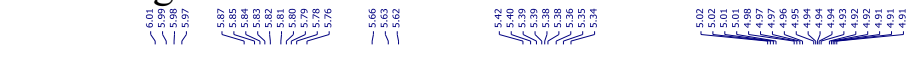

IH NMR (400 MHz, CDCG) 8 7.26, 6.01, 5.99, 5.98, 5.97, 5.87, 5.85, 5.84, 5.83, 5.82, 5.81, 5.80,

$5.79,5.78,5.76,5.66,5.63,5.62,5.42,5.40,5.39,5.39,5.38,5.38,5.36,5.35,5.34,5.02,5.02$,
$5.01,5.01,4.98,4.97,4.97,4.96,4.95,4.94,4.94,4.94,4.93,4.92,4.92,4.91,4.91,4.91,2.07$

$2.07,2.06,2.05,2.05,2.04,2.03,2.05,2.03,2.1202,2.01,2.01,1.99,1.97,1.96,1.57,1.55,1.54$,

$1.07,1.05,1.04,1.02,1.02,0.98,0.98,0.96,0.96,0.95,0.94,0.94,0.90,0.88,0.86,0.85,0.85$,

$0.84,0.83,0.81,0.77,0.77,0.76,0.74,0.73,0.72,0.71,0.71,0.70,0.07$

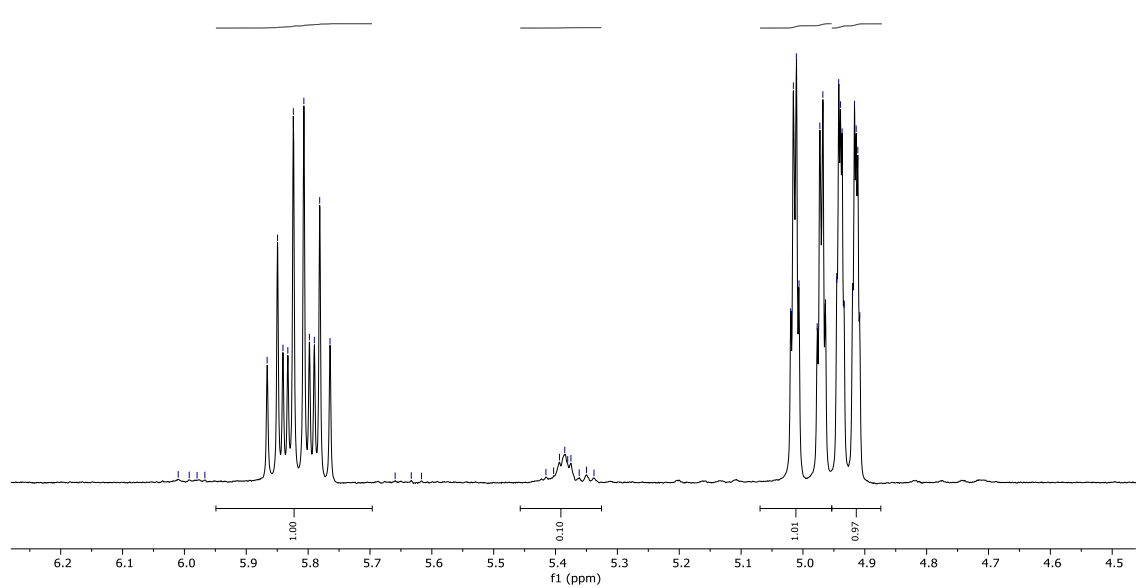




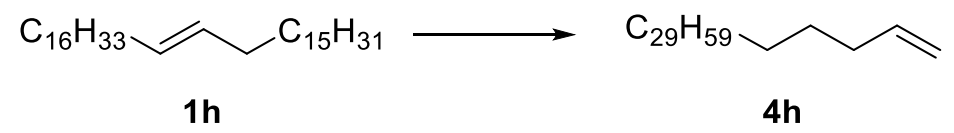

Full spectrum (crude):

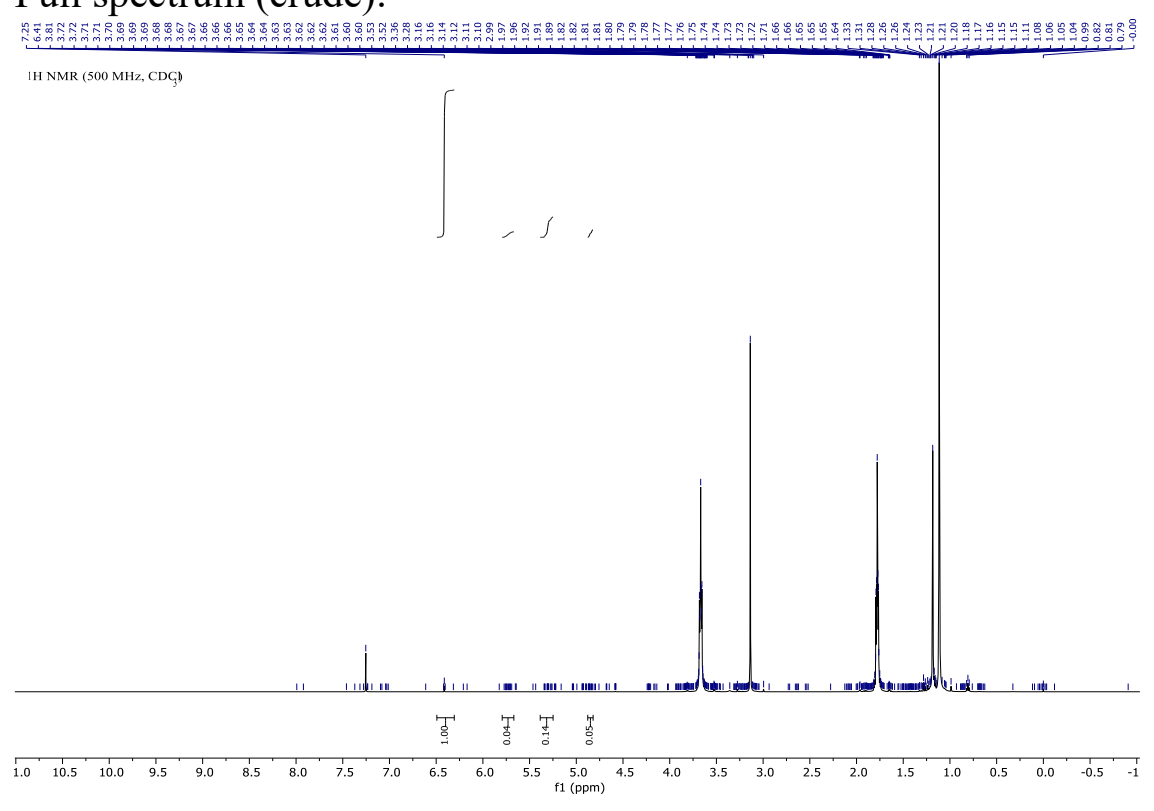

Full spectrum, zoomed up:

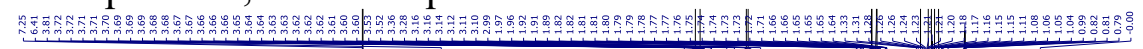

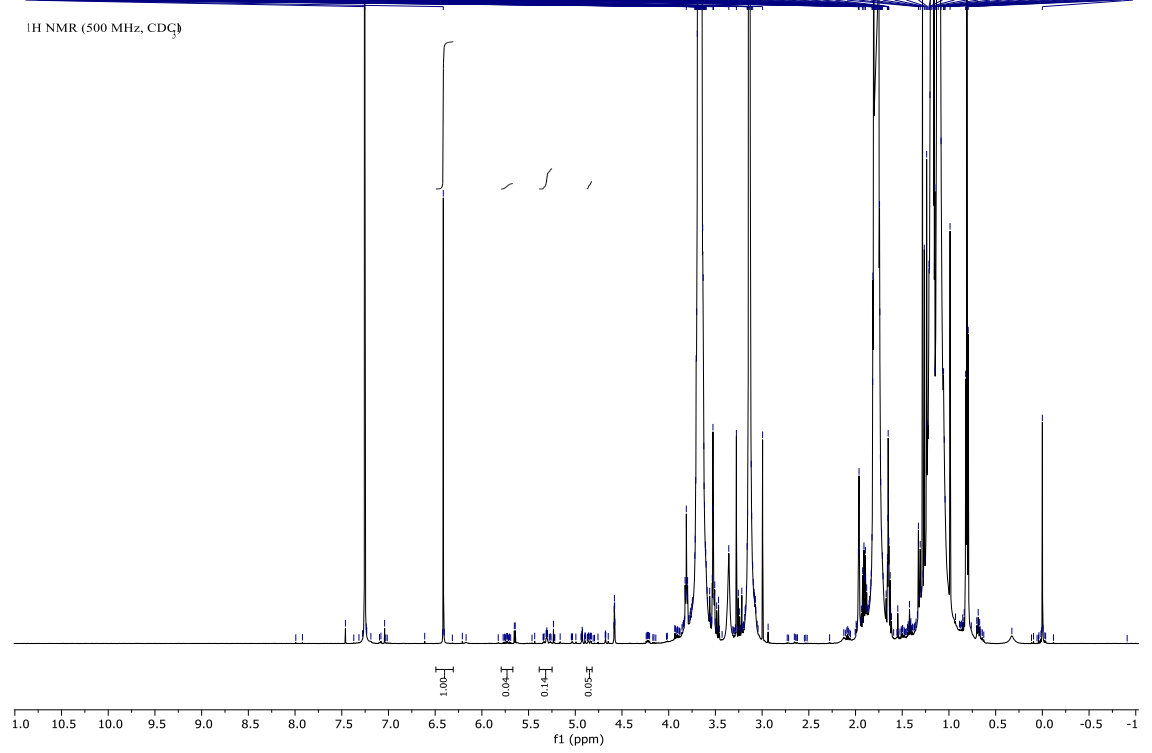


Olefins region:

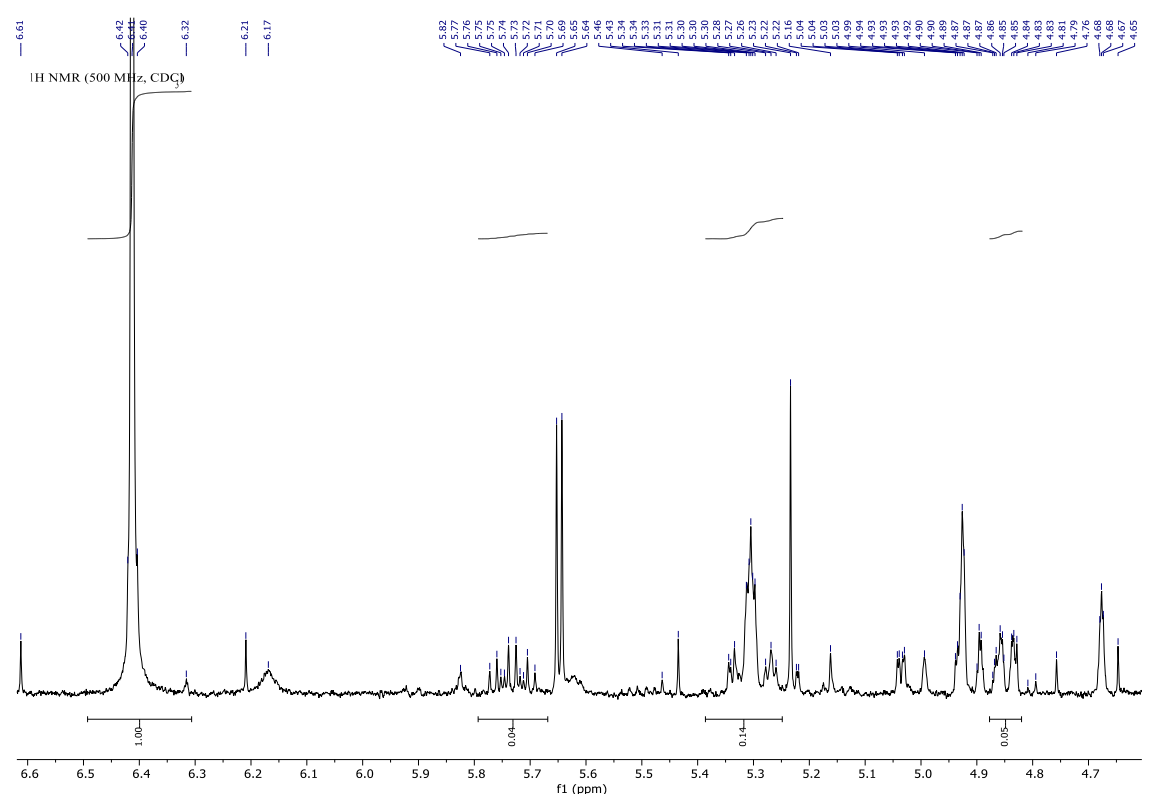




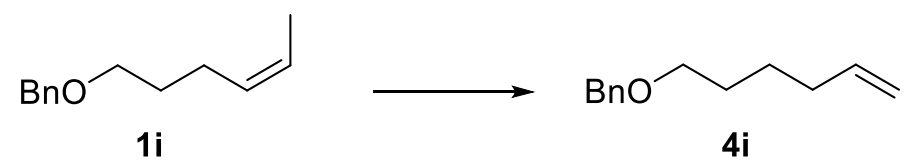

Full spectrum (crude):

IH NMR (400 MHz, CDG1) 6.35, 5.59, 5.58, 5.57, 5.56, 5.55, 5.54,

$5.28,5.22,5.21,5.20,5.18,5.17,5.16,5.15,5.14,5.13,5.12,5.11,5.09,4.77,4.76,4.76,4.76$,

4.67, 4.67, 4.66, 4.66, 4.66, 4.65, 4.65.

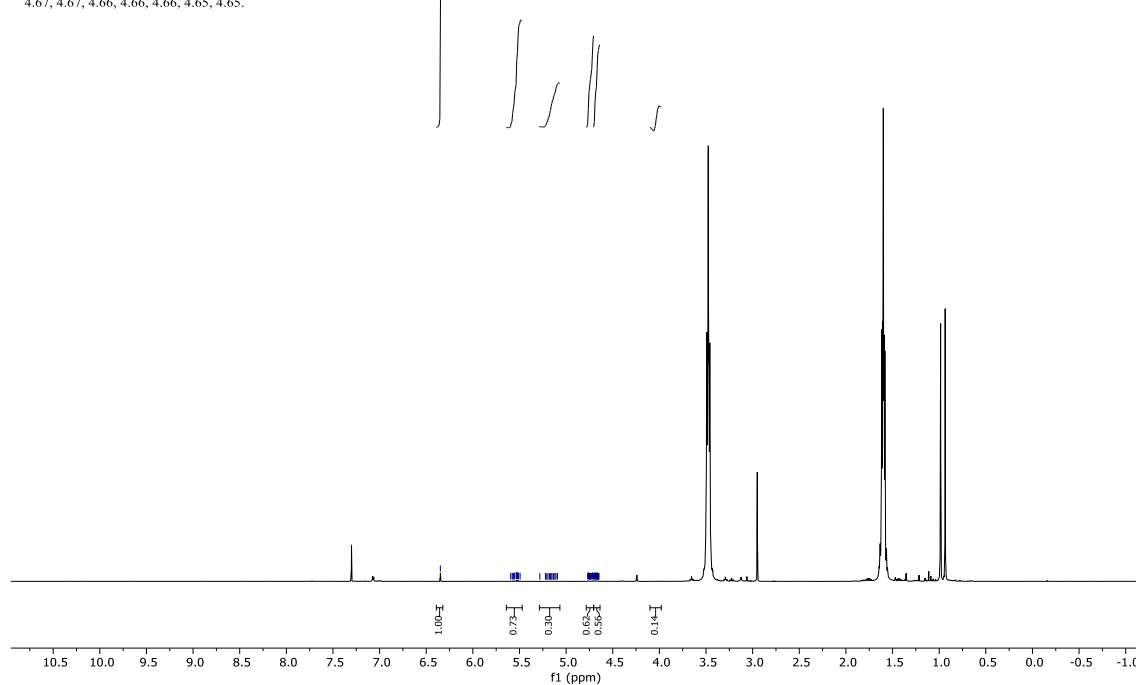

Full spectrum, zoomed up:

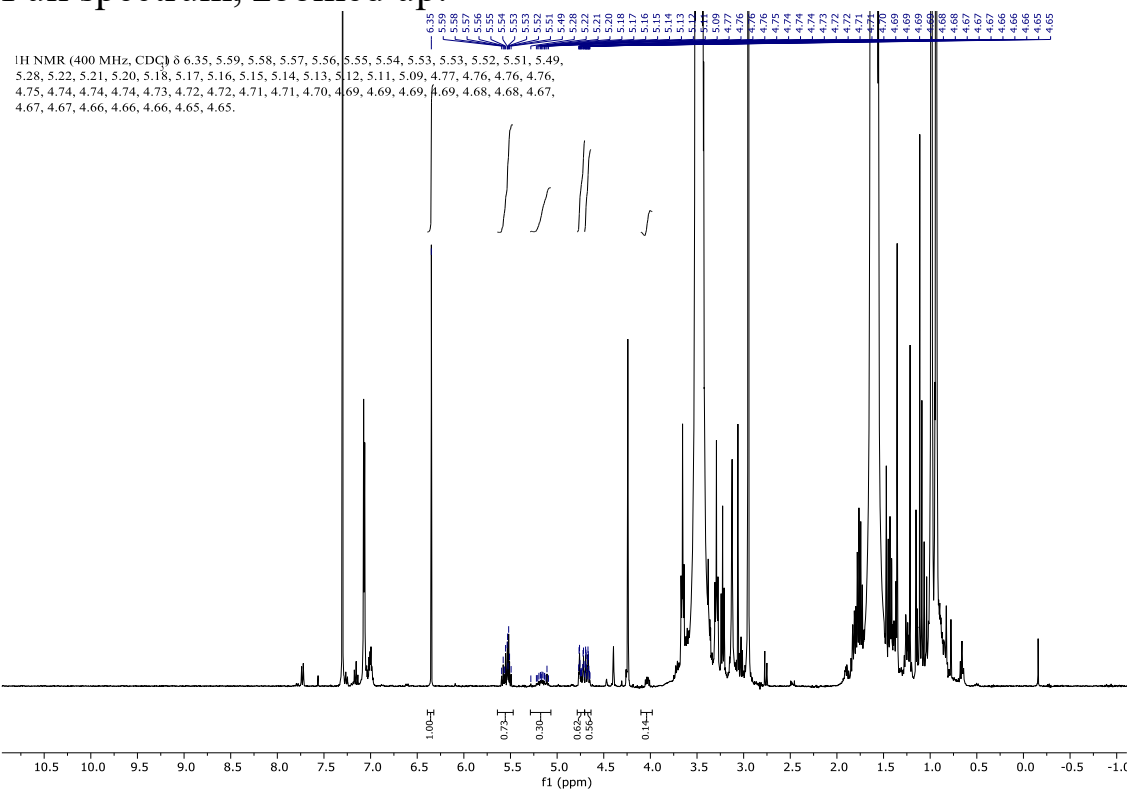




\section{Olefins region:}

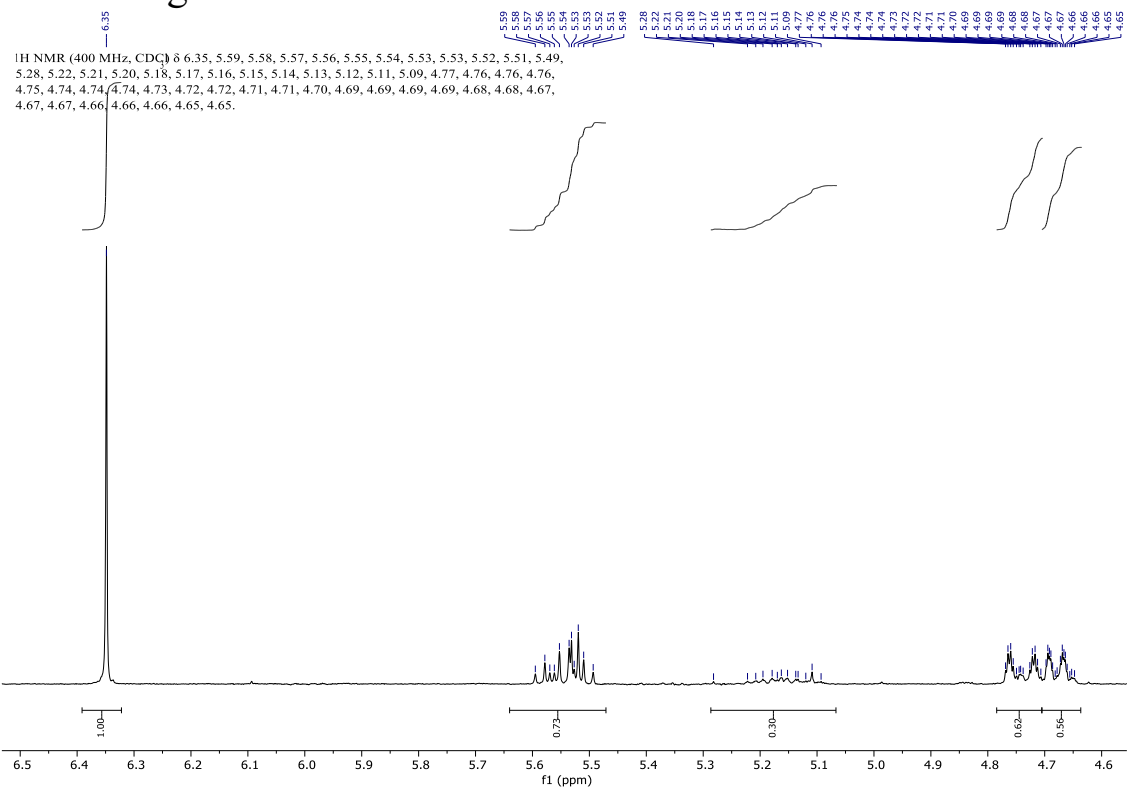


Isolation of olefin $\mathbf{4 i}$

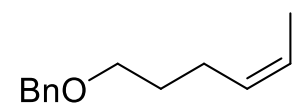

$1 \mathrm{i}$

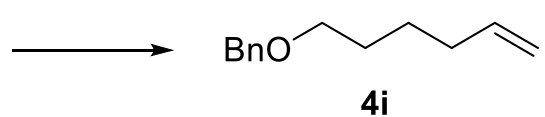

$4 \mathrm{i}$

\section{Full spectrum:}

年9

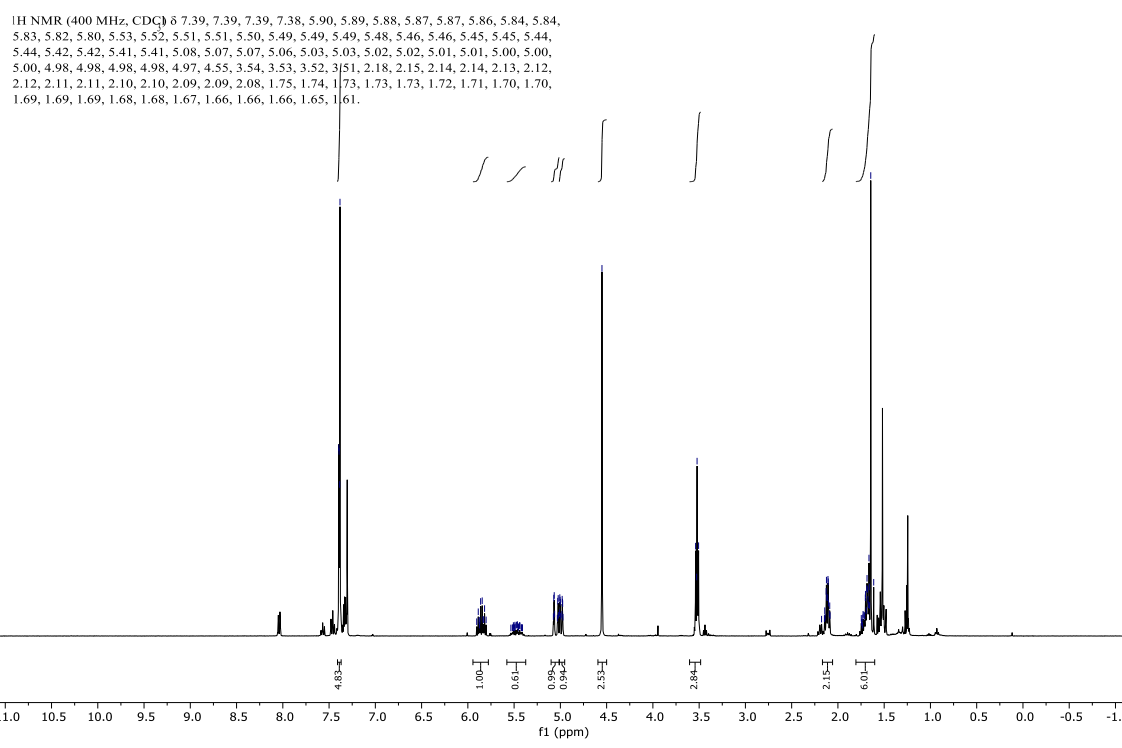

Olefins region:

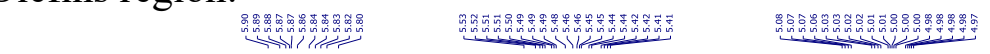

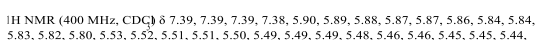

$5.44,5.42,5.42,5.41,5.41,5.08,5.07,5.07,5.06,5.03,5.03,5.02,5.02,5.01,5.01,5.00,5.00$,

$5.00,4.98,4.98,4.98,4.98,4.97,4.55,3.54,3.53,3.52,3.51,2.18,2.15,2.14,2.14,2.13,2.12$

$1.69,1.69,1.69,1.68,1.68,1.67,1.66,1.66,1.66,1.65,1.61$.

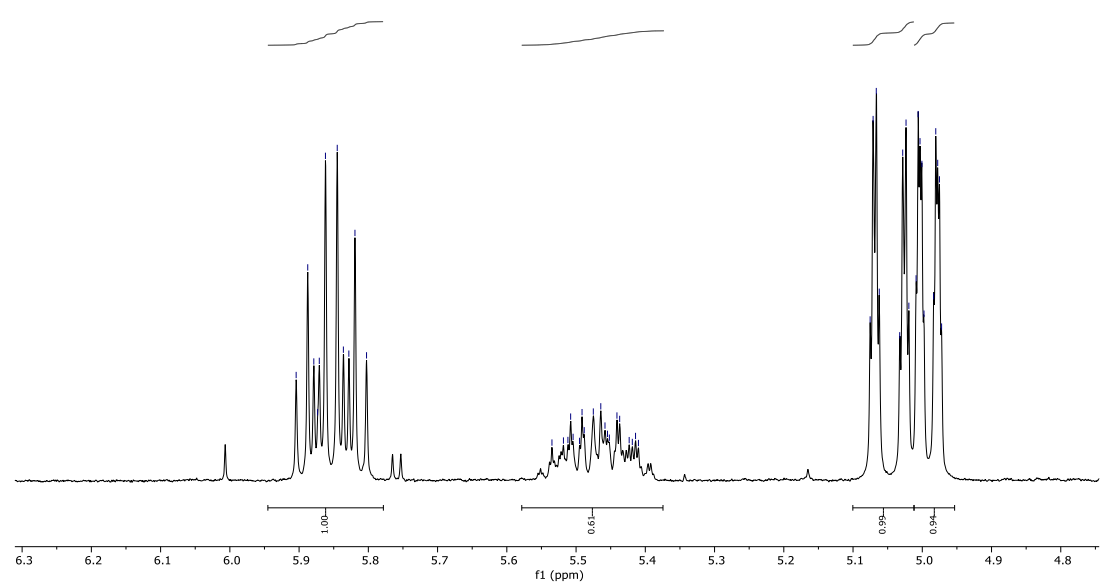

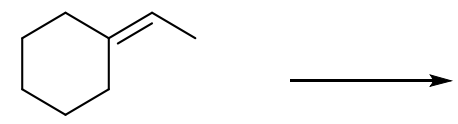

1j<smiles>C=CC1CCCCC1</smiles>

$4 \mathbf{j}$

Full spectrum (crude): 


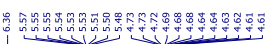

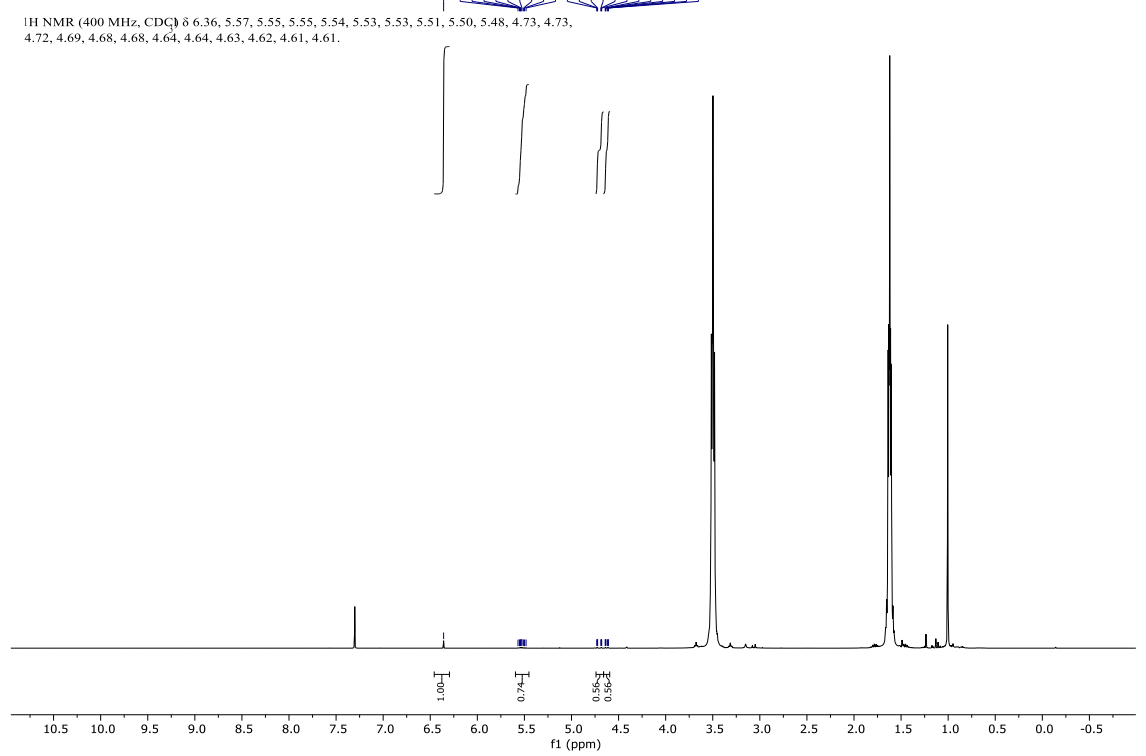

Full spectrum, zoomed up:

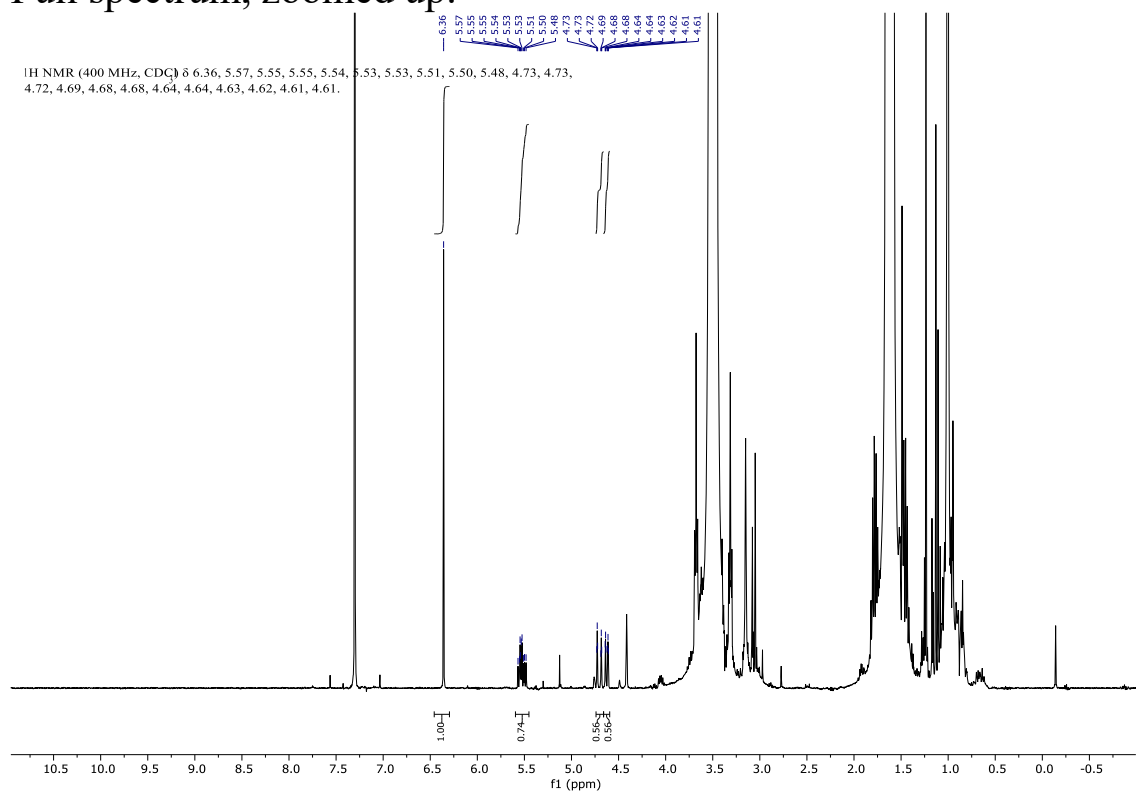




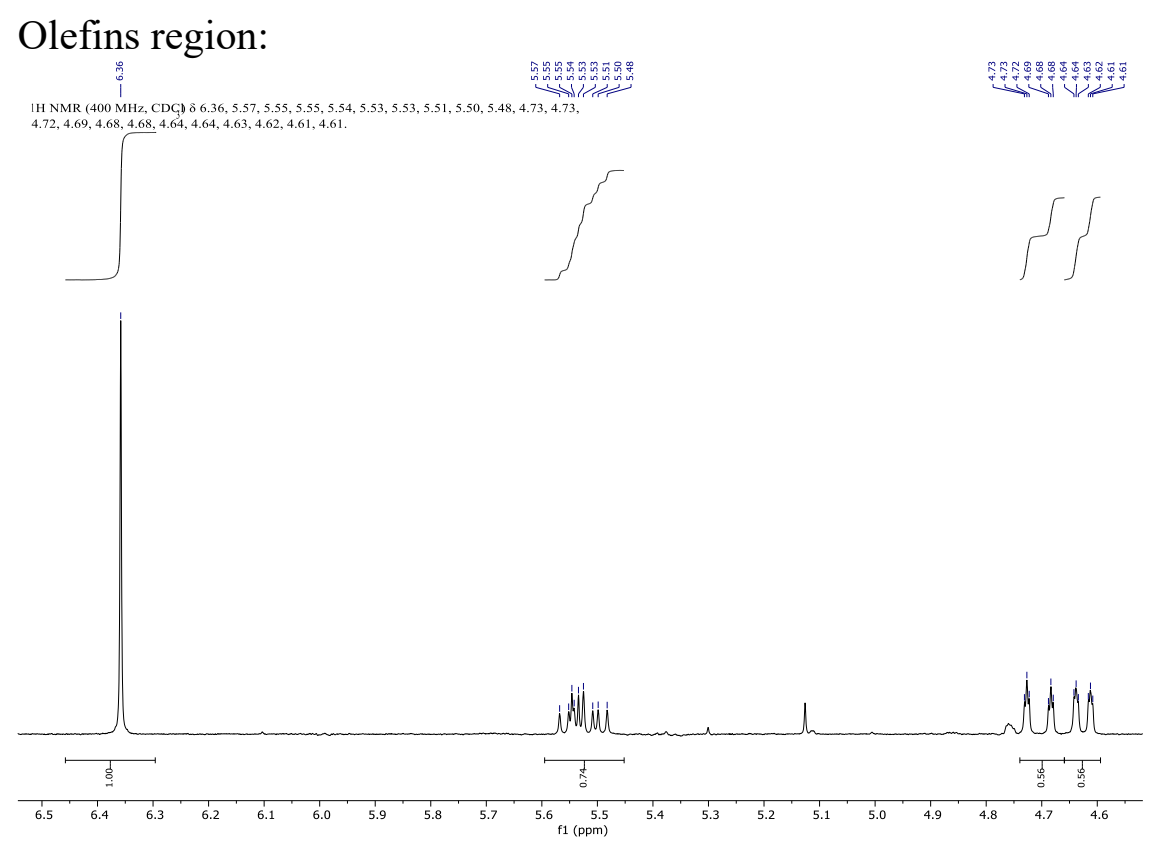




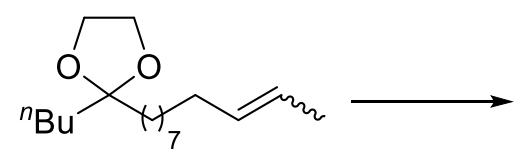

$1 k$

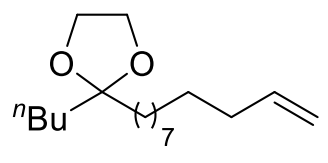

4k

Full spectrum (crude):

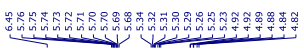

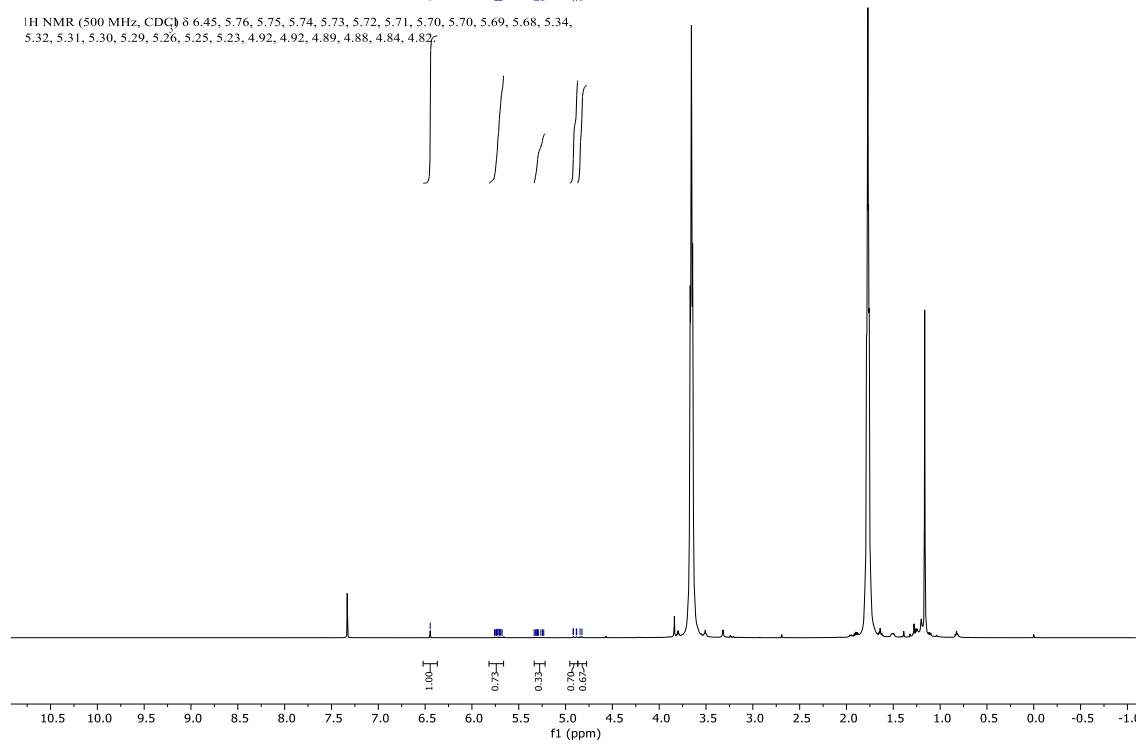

Full spectrum, zoomed up:

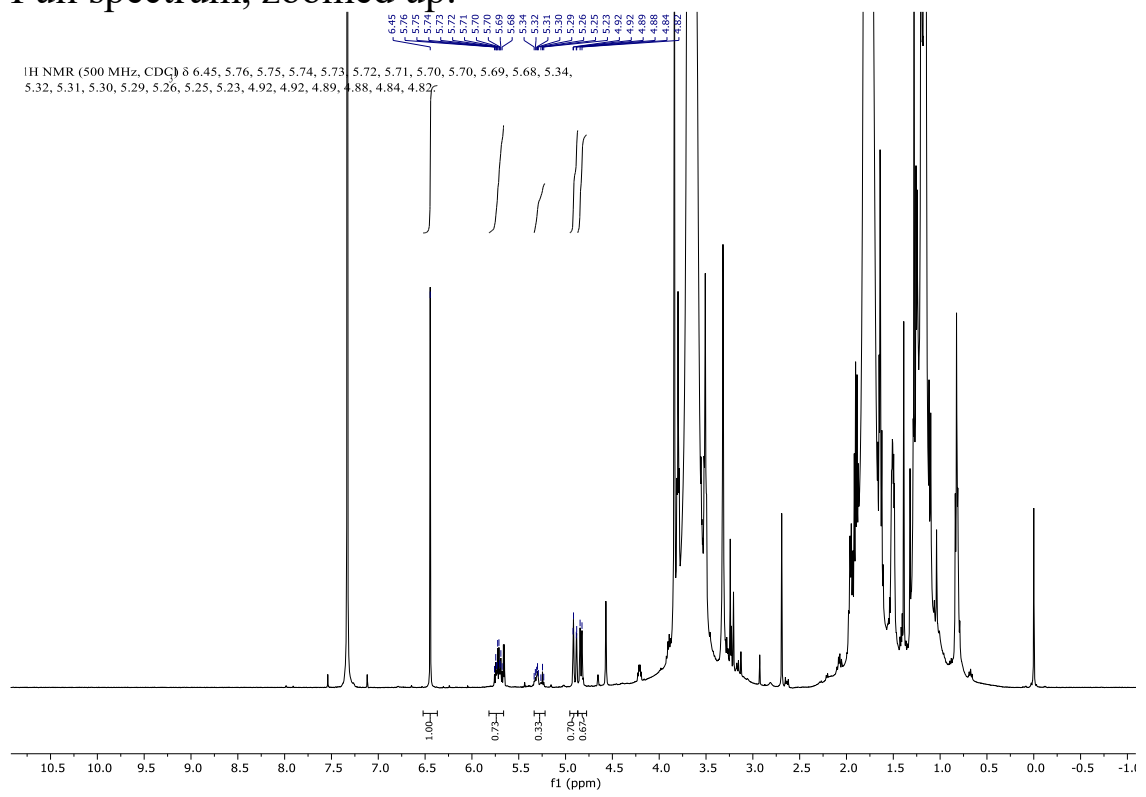




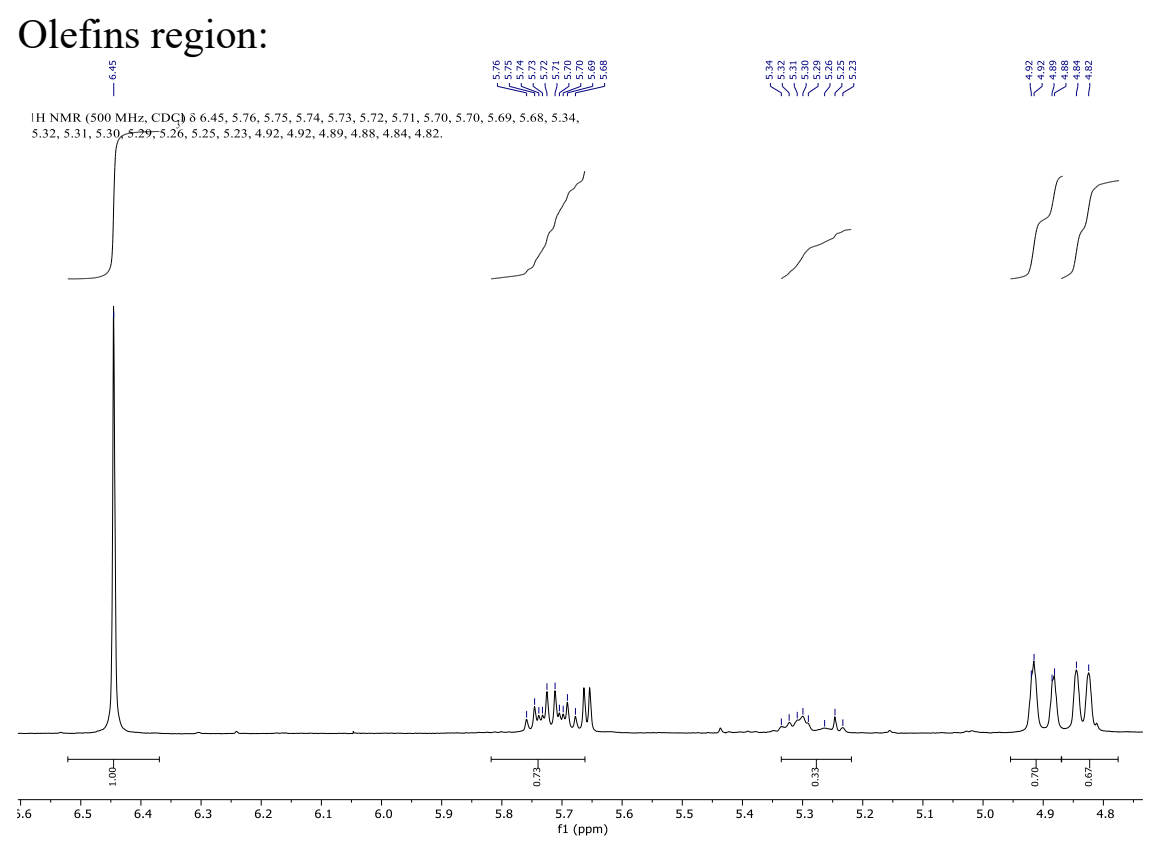


Isolation of olefin $4 \mathbf{k}$ :

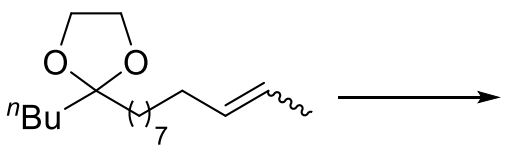

$1 \mathrm{k}$

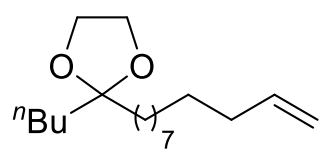

$4 k$

Full spectrum:

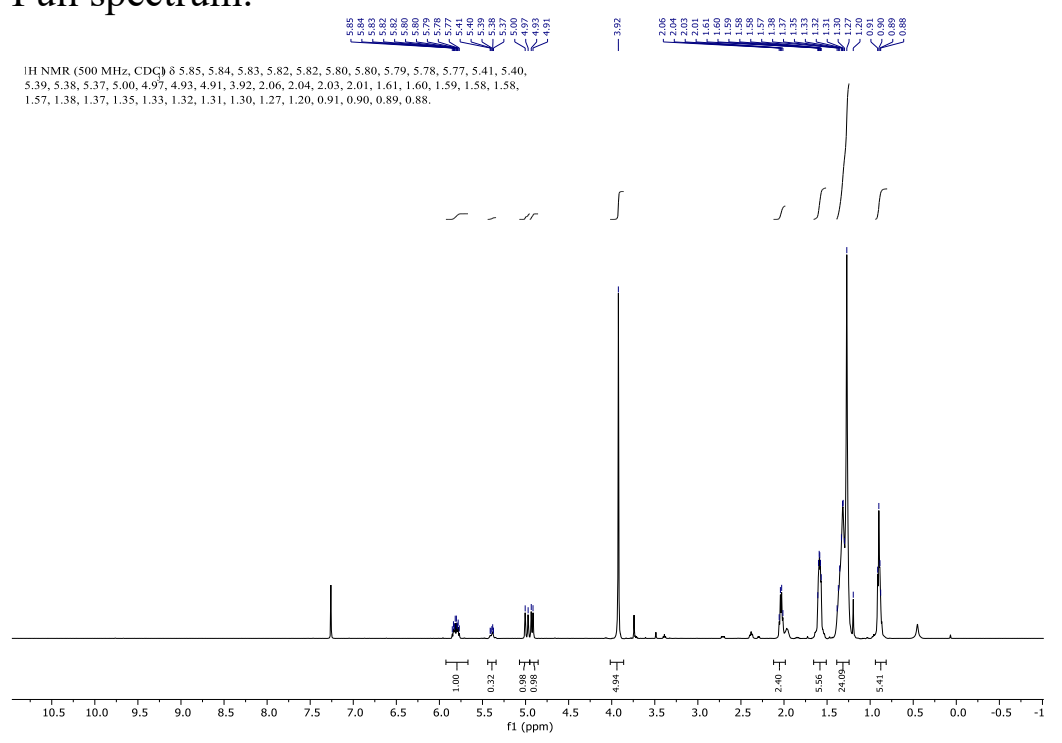

Olefins region:

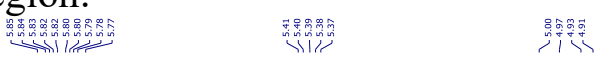

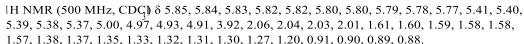

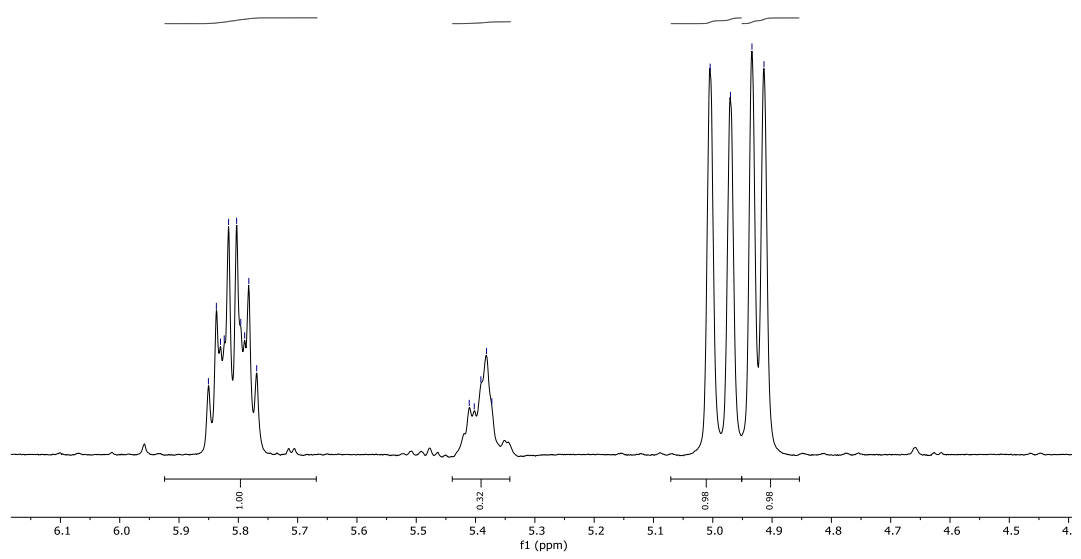

${ }^{13} \mathrm{C}$-NMR Spectrum of Olefin 4k<smiles>CCC=CCCC1([18O])OCCO1</smiles>

$1 \mathrm{k}$

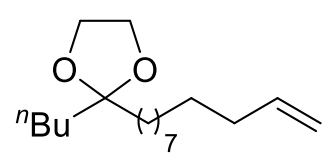

4k 


\section{Full spectrum:}
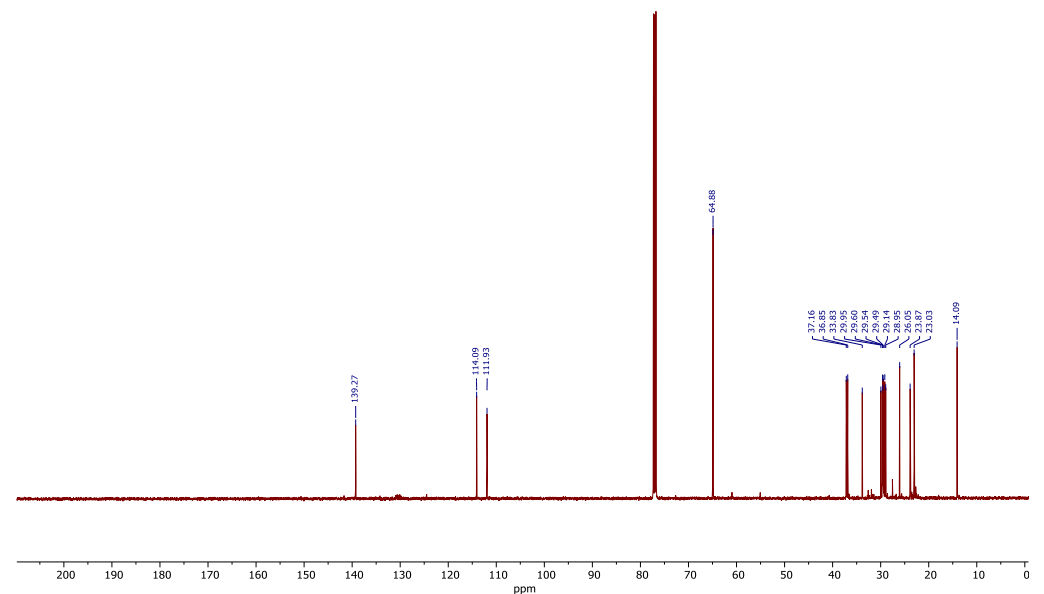

Zoomed-in spectrum:

13C NMR (126 MHz, CDCG) $8139.27,114.09,111.93,64.88,37.16,36.85,33.83,29.95,29.60$
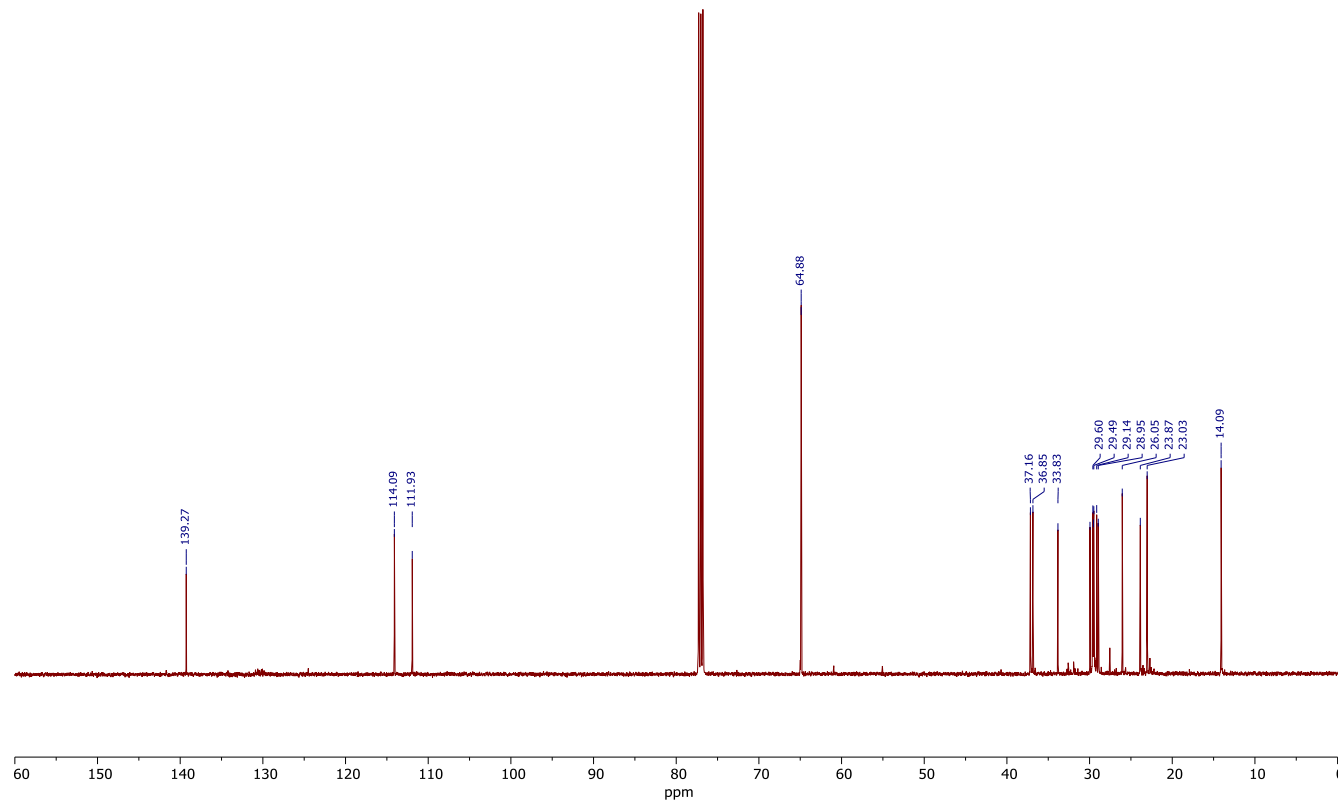

\section{GCMS Chromatogram for Olefin 1k}




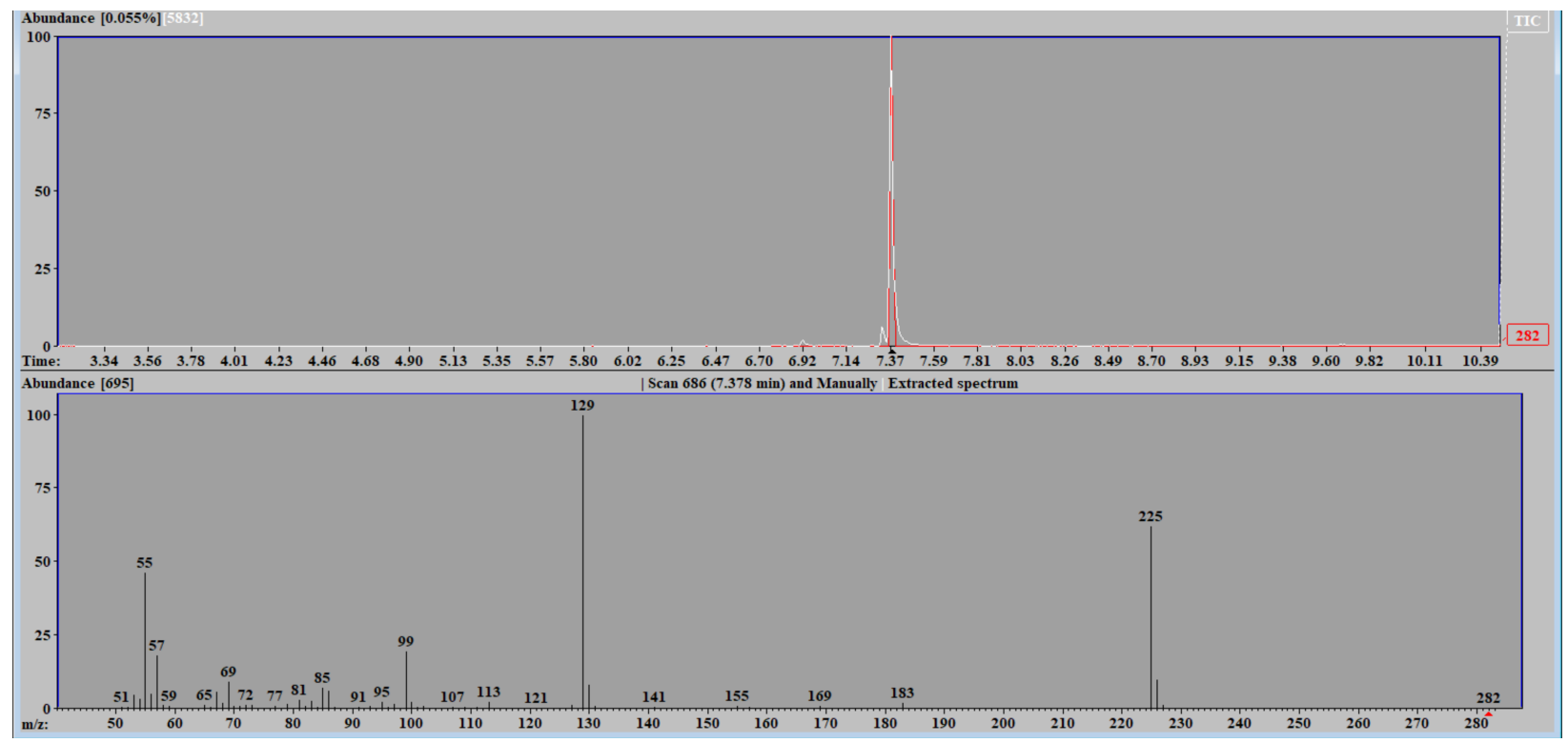<smiles>CC1=CCCC(C)(C)C1</smiles>

11
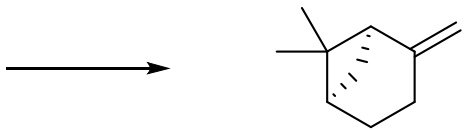

4I

Full spectrum (crude):

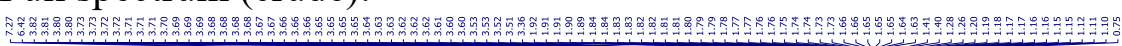

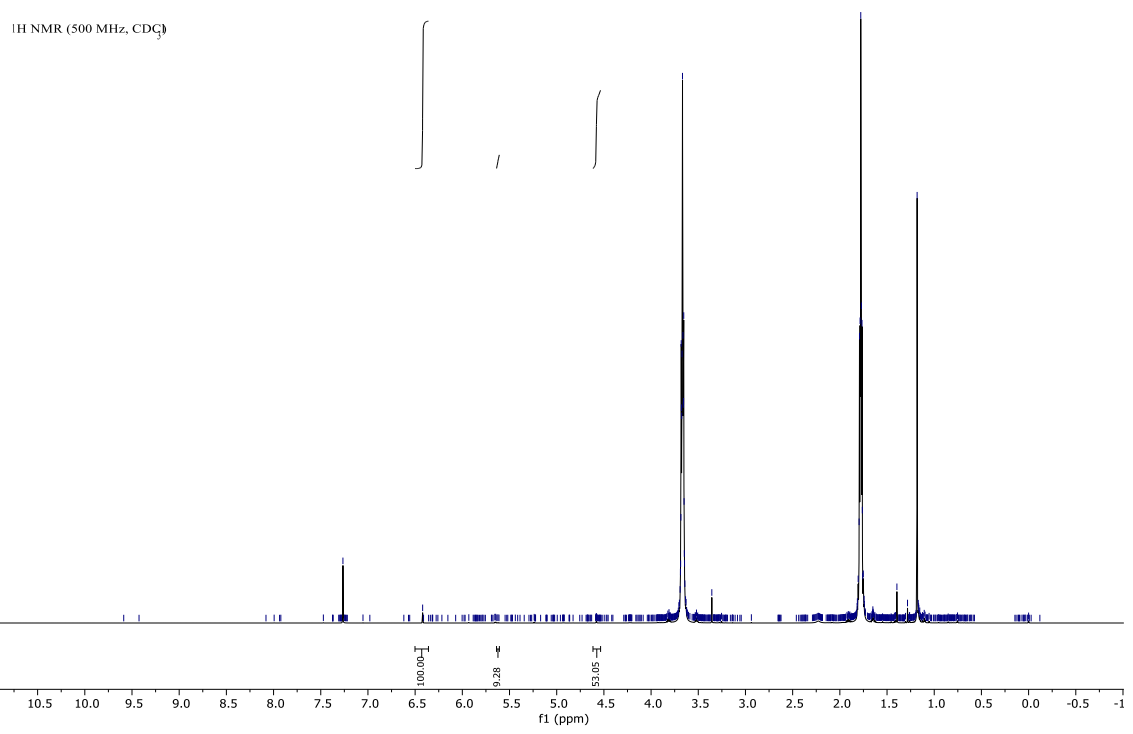

Full spectrum, zoomed up: 


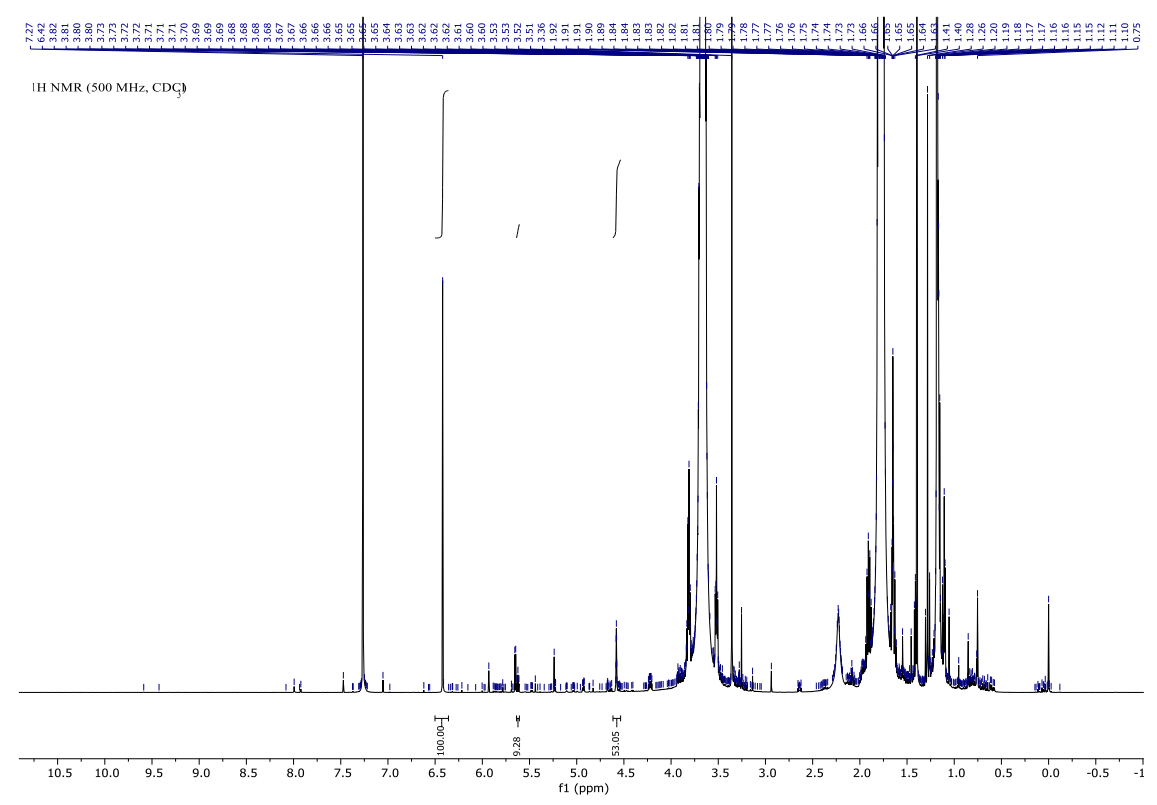


Olefins region:

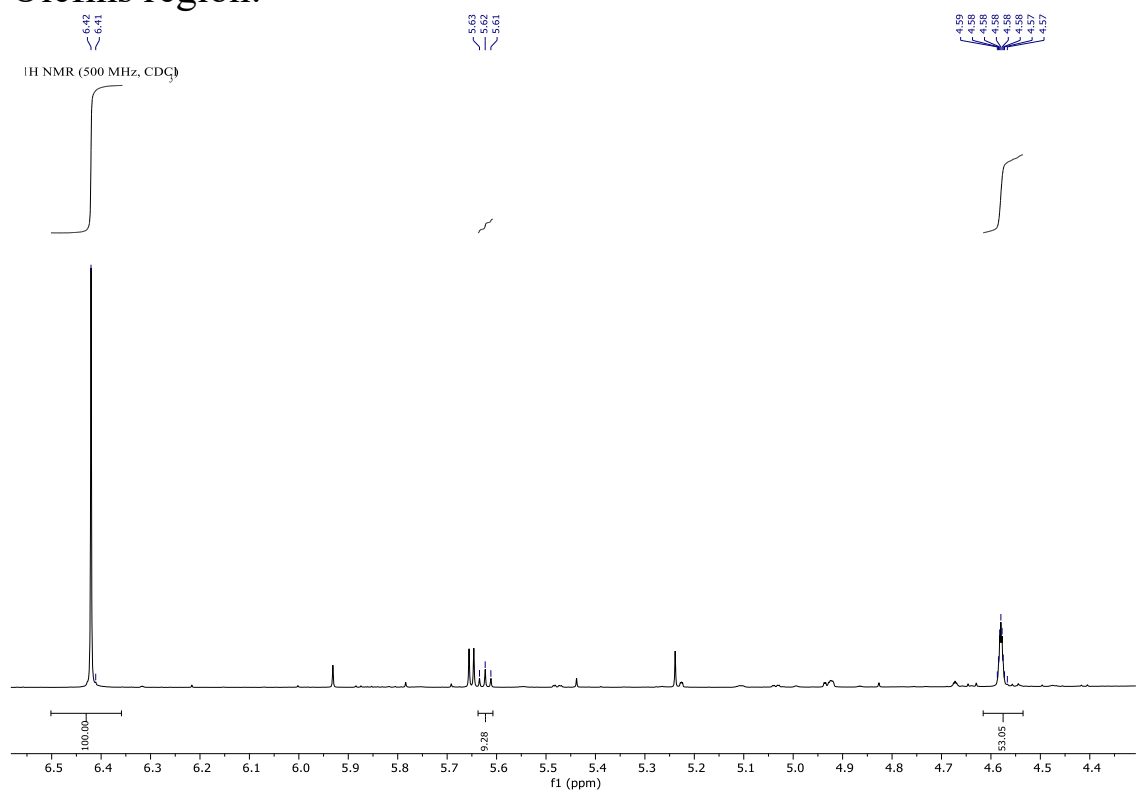




\section{Olefin Isomerization on a $1 \mathrm{mmol}$ Scale}

\section{Step 1: Hydroboration}

In a nitrogen-filled glovebox, 2-octene $(156 \mu \mathrm{L}, 1.00 \mathrm{mmol})$, MTBE $(1000 \mu \mathrm{L})$ and HBpin $(1.05$ equiv) were added to an oven-dried $20 \mathrm{~mL}$ vial equipped with a stir bar. The hydroboration catalyst C1 (10.2 mg, $2 \mathrm{~mol} \%$ ) was then added as a solid with stirring. The reaction mixture was stirred at room temperature for $24 \mathrm{~h}$.

\section{Step 2: Dehydroboration}

In a nitrogen-filled glovebox, potassium methoxide (1.00 $\mathrm{mmol}$, prepared by above procedure) and THF $(1000 \mu \mathrm{L})$ were added to the reaction mixture, and the reaction mixture was stirred for 5 min at room temperature. A solution of iodine $(1.00 \mathrm{mmol})$ in THF $(1000 \mu \mathrm{L})$ was then added, and the reaction mixture was stirred for an additional $5 \mathrm{~min}$ at room temperature. A solution of potassium tert-butoxide $(0.500 \mathrm{mmol})$ in THF $(500 \mu \mathrm{L})$ was then added, and the reaction was

stirred for a third 5-minute period at room temperature. This procedure of sequentially adding KOMe and THF, a solution of $\mathrm{I}_{2}$ in THF, and a solution of $\mathrm{KO} t \mathrm{Bu}$ in THF was repeated 3 times. After the addition of each reagent, the vial was shaken vigorously. Potassium tert-butoxide (6 equiv) and THF (2 mL) were added for the elimination, and the reaction was stirred at room temperature for $20 \mathrm{~h}$ at room temperature. The reaction mixture was diluted with $\mathrm{CDCl}_{3}(10 \mathrm{~mL}$, dropwise addition with rapid stirring), and trichloroethylene ( $89.8 \mu \mathrm{L}, 1.00 \mathrm{mmol}, 1.00$ equiv) was added. The reaction mixture was vigorously shaken, an aliquot was filtered, and a crude ${ }^{1} \mathrm{H}$ NMR spectrum was recorded. The ${ }^{1} \mathrm{H}$ NMR yield of 1 -octene was $88 \%$. 
Full ${ }^{1} \mathrm{H}$ NMR spectrum of crude reaction on $1 \mathrm{mmol}$ scale.

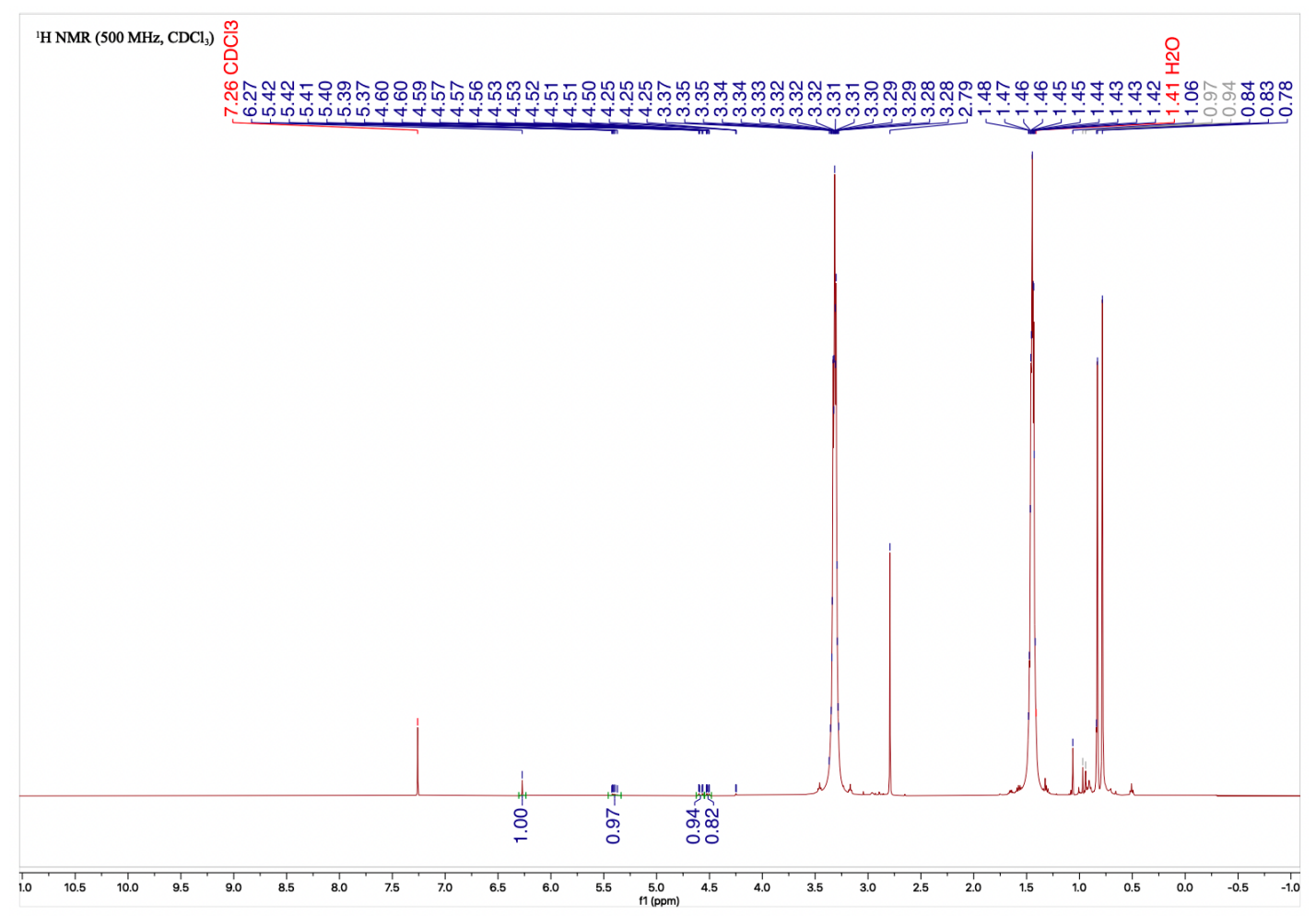

Olefins region of above spectrum:

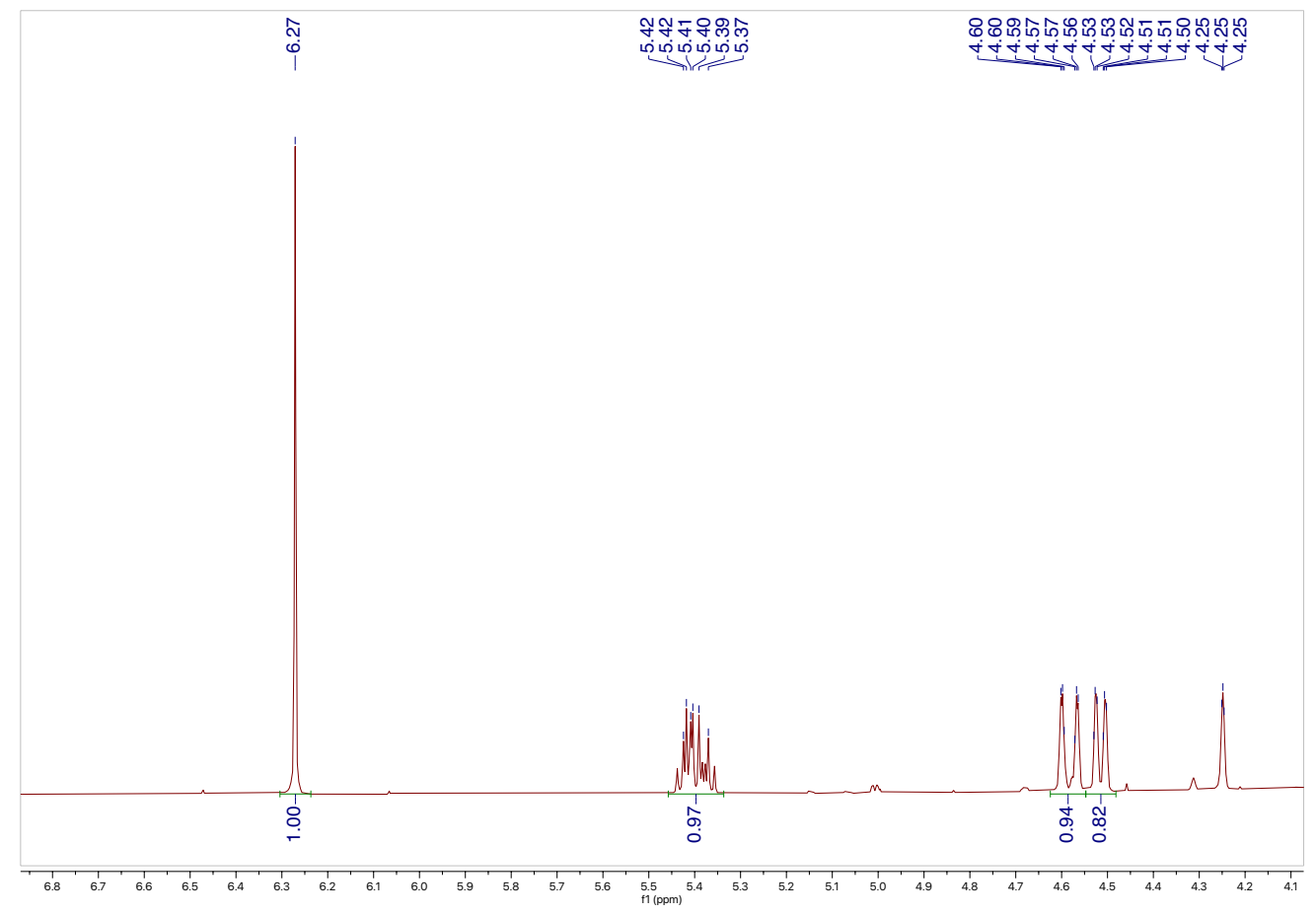




\section{References}

1. Docherty, J. H.; Peng, J.; Dominey, A. P.; Thomas, S. P. Activation and discovery of earthabundant metal catalysts using sodium tert-butoxide. Nat. Chem. 2017, 9, 595.

2. Palmer, W. N.; Diao, T.; Pappas, I.; Chirik, P. J. High-Activity Cobalt Catalysts for Alkene Hydroboration with Electronically Responsive Terpyridine and $\alpha$-Diimine Ligands. ACS Catal. 2015, 5, 622 .

3. Uchida, N.; Taketoshi, A.; Kuwabara, J.; Yamamoto, T.; Inoue, Y.; Watanabe, Y.; Kanbara, T. Synthesis, Characterization, and Catalytic Reactivity of a Highly Basic Macrotricyclic Aminopyridine. Org. Lett. 2010, 12, 5242.

4. Shuhei Kubota, M. K., Hideo Takaishi, Kenji Tsubata Method for producing diacetylpyridine derivative. JP2002212167A, 2001, 2004.

5. Obligacion, J. V.; Chirik, P. J. Bis(imino)pyridine Cobalt-Catalyzed Alkene IsomerizationHydroboration: A Strategy for Remote Hydrofunctionalization with Terminal Selectivity. J. Am. Chem. Soc. 2013, 135, 19107.

6. Inci, B.; Wagener, K. B. Decreasing the Alkyl Branch Frequency in Precision Polyethylene: Pushing the Limits toward Longer Run Lengths. J. Am. Chem. Soc. 2011, 133, 11872.

7. Schilling, J. B.; Beauchamp, J. L. Hydrocarbon activation by gas-phase lanthanide cations: interaction of praseodymium $(\mathrm{Pr}+)$, europium $(\mathrm{Eu}+)$, and gadolinium $(\mathrm{Gd}+)$ with small alkanes, cycloalkanes, and alkenes. J. Am. Chem. Soc. 1988, 110, 15.

8. Hong, J.; Radojčić, D.; Hairabedian, D.; Wan, X.; Petrović, Z. S. Alkynated and azidated octadecane as model compounds for kinetic studies of Huisgen 1,3-dipolar cycloaddition in vegetable oils. Eur. J. Lipid Sci. Technol. 2015, 117, 266.

9. Harrison, T. J.; Ho, S.; Leighton, J. L. Toward More "Ideal" Polyketide Natural Product Synthesis: A Step-Economical Synthesis of Zincophorin Methyl Ester. J. Am. Chem. Soc. 2011, $133,7308$. 